\title{
Numerical study of full-scale CFRP strengthened open- section steel columns under transverse impact
}

DOI:

10.1016/j.tws.2019.03.034

\section{Document Version}

Accepted author manuscript

Link to publication record in Manchester Research Explorer

\section{Citation for published version (APA):}

Kadhim, M. M. A., Wu, Z., \& Cunningham, L. S. (2019). Numerical study of full-scale CFRP strengthened opensection steel columns under transverse impact. Thin-Walled Structures, 140, 99-113.

https://doi.org/10.1016/j.tws.2019.03.034

\section{Published in:}

Thin-Walled Structures

\section{Citing this paper}

Please note that where the full-text provided on Manchester Research Explorer is the Author Accepted Manuscript or Proof version this may differ from the final Published version. If citing, it is advised that you check and use the publisher's definitive version.

\section{General rights}

Copyright and moral rights for the publications made accessible in the Research Explorer are retained by the authors and/or other copyright owners and it is a condition of accessing publications that users recognise and abide by the legal requirements associated with these rights.

\section{Takedown policy}

If you believe that this document breaches copyright please refer to the University of Manchester's Takedown Procedures [http://man.ac.uk/04Y6Bo] or contact uml.scholarlycommunications@manchester.ac.uk providing relevant details, so we can investigate your claim.

\section{OPEN ACCESS}




\section{Numerical study of full-scale CFRP strengthened open-section steel columns under transverse impact}

Majid M.A. Kadhim(1), Zhangjian Wu(2), Lee S Cunningham(2)

(1) College of Engineering, University of Babylon, Iraq

(2)School of Mechanical, Aerospace and Civil Engineering, University of Manchester, Manchester M13 9PL

Corresponding author: M.M.A Kadhim (majid.kadhim@manchester.ac.uk;

eng.majid.mohammed@uobabylon.edu.iq)

\section{Abstract}

In recent years, externally bonded fibre reinforced polymer (FRP) material has gained popularity as an efficient means of strengthening existing civil engineering infrastructure. In the case of steel structures, FRP has frequently been deployed to strengthen against static and fatigue loads. However, the understanding of the effect of impact load on strengthened structures is still in its early stages. In parallel with this, most of the existing studies on impact have concentrated on small scale elements. Thus, the study presented here is aimed at examining the effectiveness of carbon fibre reinforced polymer (CFRP) in strengthening full-scale steel I-section columns against impact load. To achieve this aim, a non-linear finite element model built using ABAQUS was validated against experimental tests and then used to simulate the strengthening technique. The model included failure criteria of all investigated materials (steel, CFRP and adhesive material). Various parameters including boundary conditions, preloading level, kinetic energy, impact location and impact direction were examined.

The CFRP strengthening technique was found to be highly effective in preventing column failure whether by global buckling failure or transverse shear failure. In addition the strengthened columns exhibited a reduced axial and transverse displacement by more than $70 \%$ in many cases.

\section{Keywords}

Carbon fibre reinforced polymer; steel column; dynamic loading; full-scale columns

\section{Introduction}


Columns are critical elements of any structure and their failure may lead to the catastrophic consequences of progressive collapse. Impact loads such as those derived from vehicle and ship impacts have been shown to be a significant cause of the collapse of bridge and building structures [1]. Thus, design of columns against accidental actions is increasingly requested by clients for new infrastructure, while in the case of existing structures, retrofit strengthening techniques are required to provide robustness against future accidental impacts. National standards and design codes such as Eurocode 1 are often limited to simple quasi-static approaches which may lead to substantial inaccuracies in the case of impact [2]. Recently, AlThairy [3] found that using Eurocode 1 may overestimate the axial compression resistance of columns in many cases. Based on the aforementioned discussion and since many buildings have been designed without specific provision for impact, it seems that finding an efficient strengthening technique for steel columns is a real need.

Fibre reinforced polymer (FRP) composites have been increasingly employed since the 1990s in the rehabilitation of civil engineering infrastructure due to their excellent strength-to-weight and stiffness-to-weight ratios, high durability and comparative ease of use for in-situ applications. In particular, FRP has been commonly used in the strengthening of concrete structures. More recently, the use of FRP to strengthen existing steel structures has also been adopted in field applications such as strengthening of the steel bridge on Kentucky State Highway 32 [4] in the US and the Hythe Bridge over the Thames River in Oxfordshire [5] in the UK. Several studies have proved the capability of FRP strengthening of steel members under static and fatigue loads [6-9].

Utilising FRP to enhance steel members subjected to impact loads has been very lightly studied to date. Recently, investigators have examined the effects of impact load on CFRP-steel bond strength. It has been found that the bond strength was increased under impact loading by testing 
a series of double strap joints [10]. It was also observed that the failure pattern for double strap joints comprised either CFRP delamination or CFRP rupture under impact loading, while the same joints under a quasi-static loading rate exhibited either steel and adhesive material interface failure or CFRP delamination. This was revealed to be caused by the improvement in the bond strength resulting from the increased loading rate $[10,11]$. Similar observations were also reported by Al-Mosawe, et al. [12], [13]in which different types of CFRP laminate were used including low, normal and ultra-high modulus CFRP laminates. The above findings provided an encouragement to use the CFRP strengthening technique under impact loading because it is well known that the bond between the CFRP and steel is the weakest link in this type of strengthening scheme [8].

Among the few existing studies on impact, Alam and Fawzia [14] numerically examined CFRP strengthened square hollow section (SHS) steel columns. The FE software ABAQUS was employed to simulate columns with cross sectional dimensions of $89 \times 89 \times 3.2 \mathrm{~mm}$ and length of $2380 \mathrm{~mm}$. The bond between the steel column and CFRP was unrealistically assumed to be fully bonded. The simulation results showed that the strengthening system was highly effective in buckling control of SHS columns by minimising the transverse displacement at the impact zone by about $58 \%$ when compared to un-strengthened columns. In another study, strengthening full-scale SHS $200 \times 200 \times 8.8$ columns ( $3 \mathrm{~m}$ in length) was numerically investigated by adopting various CFRP configurations including the fibres oriented in the longitudinal, transverse and longitudinal and transverse directions [15]. It was found that the average reduction in the transverse displacement at the impact zone varied from $17 \%$ to $44 \%$ depending on the CFRP configurations and preloading level (the percentage of the axial compression load to the design load). Recently two studies have experimentally investigated the dynamic behaviour of small scale CFRP strengthened square hollow steel sections [16-18]. It was found that the CFRP had a 
great improvement on the impact resistance of the columns and prevented the global buckling failure under transverse impact. All of the above studies conducted on the impact behaviour of CFRP strengthened steel columns focussed on relatively small-scale columns apart from [15]. In addition, in all cases square hollow sections were examined exclusively, whereas use of open sections, primarily $H^{\prime}$ sections are most commonly adopted for columns in everyday practice. Moreover, it was reported in previous studies $[2,19,20]$ that there are several possible failure modes of axially compressed columns with transverse impact including global buckling failure and transverse shear failure. However, the effectiveness of CFRP in preventing global buckling failure alone has been proven while to date it is not clear whether the CFRP strengthening technique is able to control transverse shear failure. Furthermore, in most of the previous studies CFRP was wrapped around SHS sections in different orientations, while this strengthening configuration may not be applicable in the case of $\mathrm{H}^{\prime}$ sections. In view of all that has been mentioned so far, a comprehensive understanding of the dynamic response of CFRP strengthened H' section steel columns is needed. Towards this, a numerical model built using ABAQUS will be validated and subsequently used to investigate the focussed strengthening method. The first validation study models experimental work undertaken in an earlier study by the present authors [17], the second is from experiments conducted by Yu and Jones [20] and the third study simulates experimental work originally carried out by Zeinoddini, Parke and Harding [19].

\section{Validation of the numerical model}

The aim of this section is to confirm the capability of the ABAQUS/Explicit model to accurately capture the response of CFRP strengthened steel members and predict various failure modes of 
axially compressed steel columns under transverse impact. The numerical model is validated by simulating 3 separate experimental studies.

\subsection{Validation 1: CFRP strengthened steel columns under impact load}

Here the experimental programme comprised testing a number of CFRP strengthened square hollow section (SHS) under impact load [17]. In this section, only three samples were chosen for comparison. Two layers of $0.6 \mathrm{~mm}$ thick CFRP sheets with $0.8 \mathrm{~m}$ length were longitudinally wrapped around $0.85 \mathrm{~m}$ long steel columns. Two end plates $(0.14 \times 0.14 \mathrm{~m})$ had been welded to the steel section prior applying the CFRP. All samples were tested under a constant kinetic energy generated by a $91 \mathrm{~kg}$ mass dropped by $4.43 \mathrm{~m} / \mathrm{sec}$ velocity. Three different axial compressive preloading levels, which represent the ratio between the applied load and design ultimate load of the column (in accordance with Eurocode 3 [21] ), were applied to the tested samples: 0, 50 and 70\% which are labelled as CL0, CL50 and CL70 respectively. The precompression force was applied using a disc spring pile technique described in detailed in [17].

\subsubsection{Numerical model description}

The steel columns and CFRP were modelled using 4-node shell elements (SR4) with reduced integration and hourglass control while the other steel components such as the indenter and supports were modelled using 8-node solid elements (C3D8R). Cohesive elements with 8-node reduced integration points were employed to introduce the adhesive material in the numerical model. A mesh sensitivity study was conducted ensure the independence of the results from the computational mesh. It was found that $1.5 \mathrm{~mm}$ and $5 \mathrm{~mm}$ for the impact region and the rest of the column height respectively provided reasonable results and further refinements did not have a noticeable effect. The typical modelling of steel in the present study comprises both strain hardening and strain rate effects. Isotropic strain hardening is adopted in this study to represent 
the strain hardening behaviour of steel. The classical metal (von Mises) plasticity model was employed to simulate the isotropic strain hardening of the material. The strain rate effect for steel was introduced using the Cowper-Symonds model with material parameters of $D=40.4$ sec-1 and $\mathrm{q}=5$ [22]. The average yield and ultimate stresses of steel were 538.8 and $611.1 \mathrm{MPa}$ respectively and the average modulus of elasticity was $185 \mathrm{GPa}[23]$.

The modelling of CFRP proceeded in three stages. In the first stage linear elastic response of unidirectional CFRP was defined using a lamina model in ABAQUS/Explicit, while in the second and third stages the initiation and evolution of damage were defined using Hashin's failure criteria [24]. The main inputs for the CFRP modelling are listed in Table 1 based on the type of CFRP used in this experiment and in other research [26] this being Toho Tenax STS40. The adhesive material was modelled as a traction-separation model which is commonly used for similar cases $[11,12]$. Similarly, the adhesive material modelling can be divided into three parts: linear elastic response, damage initiation criterion and damage evolution law. The adhesive material thickness and type were reported in Kadhim, Wu and Cunningham [17] as $0.88 \mathrm{~mm}$ and Araldite 420 respectively. The input data of the cohesive elements are listed in Table 2 [25].

Table 1: Material properties of the CFRP sheet

\begin{tabular}{|l|l|}
\hline Property & Value \\
\hline Density* & $1600 \mathrm{~kg} / \mathrm{m} 3$ \\
\hline E1 Elastic modulus in the longitudinal direction** & $105.3 \mathrm{GPa}$ \\
\hline E2 Elastic modulus in the transverse direction* & $17 \mathrm{GPa}$ \\
\hline G12 In-plane shear modulus* & $6 \mathrm{GPa}$ \\
\hline Longitudinal tensile strength** & $1397.8 \mathrm{MPa}$ \\
\hline Longitudinal compressive strength* & $1200 \mathrm{MPa}$ \\
\hline Transverse tensile strength* & $50 \mathrm{MPa}$ \\
\hline Transverse compressive strength* & $250 \mathrm{MPa}$ \\
\hline
\end{tabular}




\begin{tabular}{|l|l|}
\hline Longitudinal shear strength* & $70 \mathrm{MPa}$ \\
\hline
\end{tabular}

*material properties were obtained from Dolce [26],

**material properties were obtained from [17]

Table 2: Input data for the cohesive elements [25]

\begin{tabular}{|l|l|}
\hline Property & Value \\
\hline Stiffness in the normal direction* & $1315.6 \mathrm{~N} / \mathrm{mm}$ \\
\hline Stiffness in the $1^{\text {st }}$ and $2^{\text {nd }}$ shear directions* & $642.4 \mathrm{~N} / \mathrm{mm}$ \\
\hline Tensile strength & $29 \mathrm{MPa}$ \\
\hline Shear strength & $27.5 \mathrm{MPa}$ \\
\hline Elongation at break & $4.6 \%$ \\
\hline
\end{tabular}

*The values of stiffness $=$ elastic modulus (or shear modulus) $\times$ thickness of cohesive layer [27], where the values of elastic modulus and shear modulus of adhesive material were gained from manufacturer datasheet [25]

\subsubsection{Validation 1 Results}

The impact force-time histories for dynamically loaded samples at mid-span are plotted in Figure 1. It can be seen from this figure that the impact force history is reasonably predicted by the numerical model. For instance, the impact duration predicted by the numerical model for sample CL0 was $10 \%$ less than the corresponding value obtained from the physical test. This divergence seems to be less significant for those with $50 \%$ and $70 \%$ preload. It can also be noticed from Figure 1(D) that the numerical results give a high level of accuracy when compared with the corresponding experimental results regarding the transverse displacement time history. In order to ensure that the numerical model is able to capture the whole behaviour of the analysed samples, the deformed shape of the impact zone was plotted in Figure 1(E). It should be noted that in the experiment no global failure occurred for the tested samples [17] but local steel buckling and CFRP damage occurred in the region of the impact. This comparison demonstrated that damage for the CFRP in the impact region was accurately captured by the numerical model. 

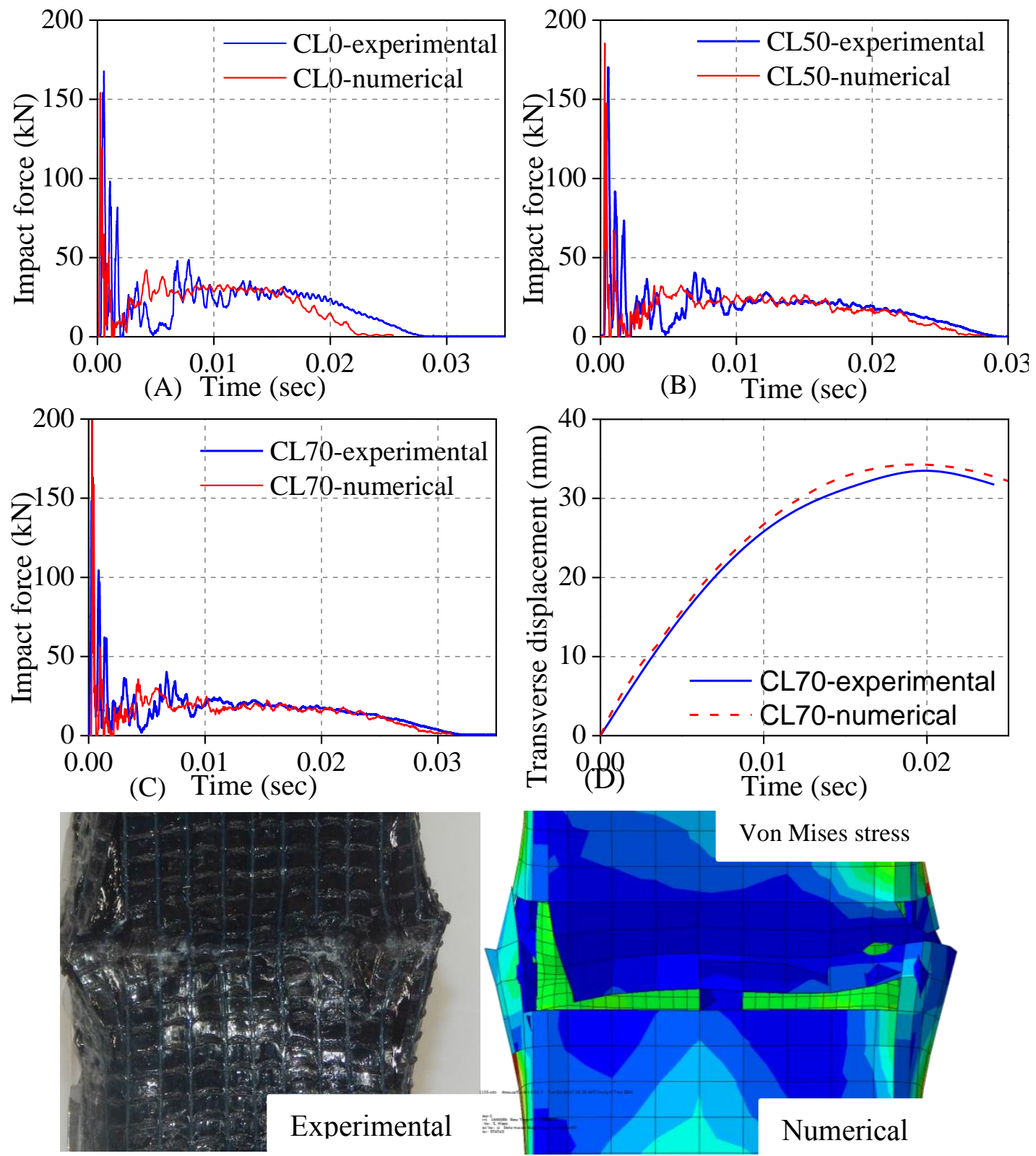

(E)

Figure 1: Comparison between the experimental and numerical results: impact force-time histories for samples (A) CL0; (B) CL50 and (C) CL70, (D) transverse displacement history for sample CL70 and (E) the damage in the impact zone for sample CL50.

\subsection{Validation 2: Shear failure of steel beams}

The experimental results for steel beams subjected to impact load presented by $\mathrm{Yu}$ and Jones [20] are simulated in this section to validate the capability of the proposed numerical model to capture shear failure. The experimental programme included testing a set of fully clamped steel rectangular solid beams $(10.17 \times 6.2 \mathrm{~mm})$ across a span $101.6 \mathrm{~mm}$. Two positions of impact were 
selected i.e. 25.4 and $49.9 \mathrm{~mm}$ measured from the left support for beams SB07 and SB08 respectively. The velocity of a $5 \mathrm{~kg}$ impactor was $8.8 \mathrm{~m} / \mathrm{sec}$ and $10.6 \mathrm{~m} / \mathrm{sec}$ for beams SB07 and SB08 respectively.

\subsubsection{Numerical model description}

The steel beams and the impactor were modelled using the brick element C3D8R with $1 \mathrm{~mm}$ element size at the impact zone and beam ends and $2 \mathrm{~mm}$ at the rest of the beam. The values of the modulus of elasticity and Poisson's ratio were $208 \mathrm{GPa}$ and 0.3 respectively. The material modelling of the steel beam was the same with that described for Validation 1. For the constants of the Cowper-Symonds model, the following values were used as reported by [20] $D=1.05 \times$ $10^{-7} \sec ^{-1}$ and $\mathrm{q}=8.30$.

ABAQUS/Explicit offers a capability for modelling progressive damage in ductile metals which can be used in conjunction with the von Mises model, stain rate dependence and other plasticity models [27]. When the criteria of the damage initiation are met, the material stiffness is degraded progressively depending on the damage evolution response that should be defined in the material modelling. The shear damage initiation criterion is met when the following condition is satisfied:

$\omega_{s}=\frac{\sum \Delta \varepsilon^{p l}}{\varepsilon_{s}^{p l}}=1$

Where $\sum \Delta \varepsilon^{p l}$ is the accumulative value of equivalent plastic strain.

The procedure of using this type of damage initiation criterion was reported in a previous study [2] to be undertaken in two steps. In the first step, a nonlinear finite element analysis was performed using ABAQUS/Explicit under the same loading condition but using the metal plasticity model only. This step is performed to obtain the values of strain rate and shear stress 
ratio corresponding to this loading condition which are required to define the shear progressive damage. Next, these values (shear stress ratio and strain rate) extracted from the first step will be used together with the fracture strain value which is obtained from true stress-strain curve. The second step is performed by using all of the above values as input data (see Table 3) in the material damage model.

In summary the values in Table 3 can be divided into two groups. The first group represents the values of plastic strain at damage initiation and strain at complete failure. These strain values can be obtained from the stress-strain curve of the material (see Figure 2). The second group which represents the values of maximum shear stress ratio and maximum strain rate can be extracted from a nonlinear finite element analysis by using the metal plasticity model only as described in the previous paragraph. These values are obtained directly from the ABAQUS simulation. It should be noted that the value of effective plastic displacement can be determined as in equation

$$
u_{f}^{p l}=L_{c} \varepsilon_{f}^{p l}
$$

Where $L_{c}$ is the characteristic length of the element defined as the square root of the integration point area of the shell elements and the cubic root of the volume integration point of the solid elements [27], and $\varepsilon_{f}{ }^{p l}$ represents the strain at the complete failure of the material.

When the damage initiation criterion has been reached at any element, the damage starts and the degradation of the material stiffness of the element continues until failure. Damage evolution based on effective plastic displacement is adopted in this study because it helps to decrease the mesh dependency of the results [28].

\section{Table 3: Steel shear damage parameters used in the current numerical model}




\begin{tabular}{|l|l|l|l|l|l|}
\hline Case & $\begin{array}{l}\text { Plastic strain } \\
\text { at damage } \\
\text { initiation }\end{array}$ & $\begin{array}{l}\text { Maximum } \\
\text { shear } \\
\text { stress ratio }\end{array}$ & $\begin{array}{l}\text { Maximum } \\
\text { strain rate } \\
(\text { sec-1) }\end{array}$ & $\begin{array}{l}\text { Strain at } \\
\text { complete } \\
\text { failure }\end{array}$ & $\begin{array}{l}\text { Effective plastic } \\
\text { displacement } \\
(\mathrm{m})\end{array}$ \\
\hline Validation 2 & 0.164 & 2 & 179 & 0.825 & 0.0004125 \\
\hline $\begin{array}{l}\text { CFRP strengthened } \\
\text { H' section }\end{array}$ & 0.164 & 2 & 16 & 0.2 & 0.0022 \\
\hline
\end{tabular}

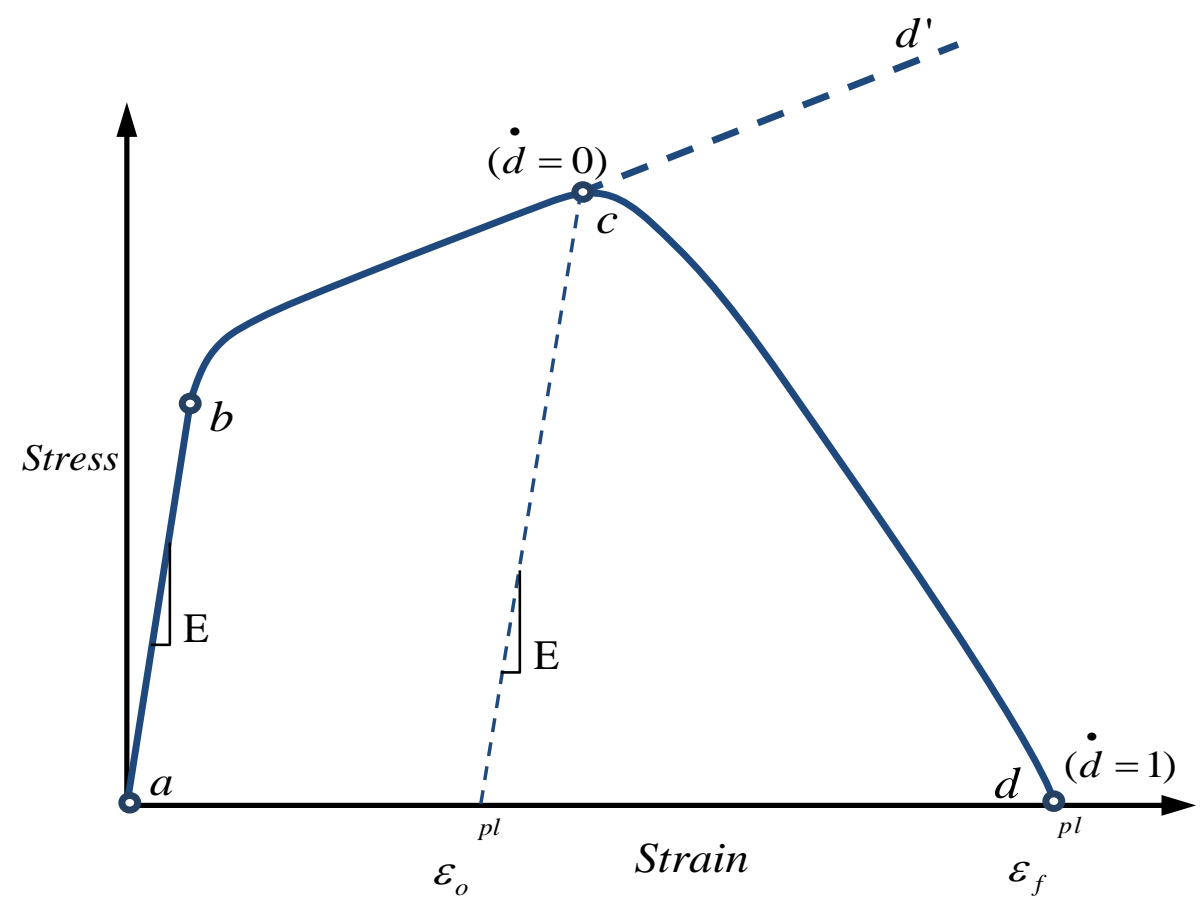

Figure 2: Typical uniaxial stress-strain curve of the steel with progressive damage degradation, based on [27]

\subsubsection{Validation 2 Results}

The experimental transverse displacement-time history for the sample loaded dynamically at the one-quarter span position (SB07) together with the associated numerical curve is shown in Figure 3(A). Very good correlation is obtained from the numerical simulation regarding the transverse displacement-time history. In addition, the transverse displacement obtained from the simulation at the instant of failure for beam SB08 was $21.6 \mathrm{~mm}$ which is in a high level of correlation when compared to the corresponding experimental value $(21.8 \mathrm{~mm})$ [20]. 
In terms of strain distribution, the strain obtained from the numerical simulation shows a good match compared to the corresponding experimental strain as shown in Figure 3(B), which illustrates the experimental strain reading for the strain gauge attached to the lower surface of beam SB08 together with the corresponding numerical result.

It is evident from Figure 3(C) that the maximum values of the shear damage initiation criterion are located at the beam mid-span where the impact occurred while the beam ends exhibited lower damage initiation criterion values during all impact duration (note a value of 1.0 indicates failure). This was completely in agreement with the experimental results when the shear failure occurred at the beam mid-span as shown in Figure 3(D).

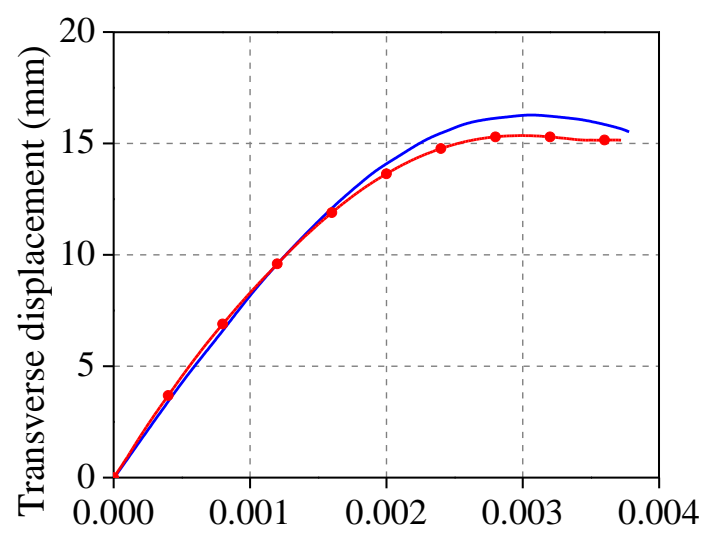

(A) Time (sec)

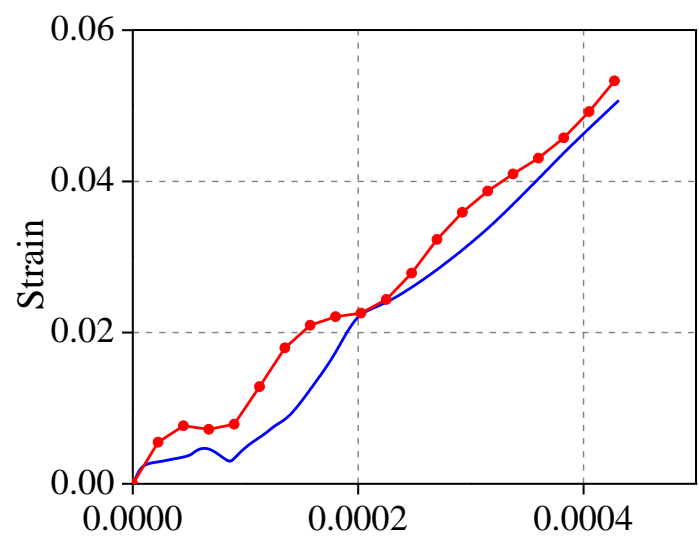

(B) Time (sec)

Experimental (Yu and Jones, 1991) — Numerical simulation results

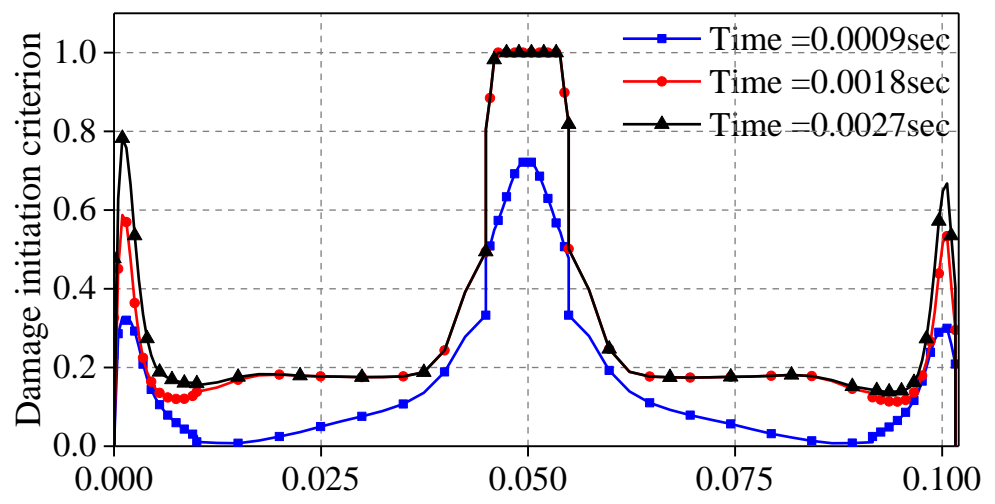

Longitudinal distance along the bottom of the beam $(\mathrm{mm})$

(C) 


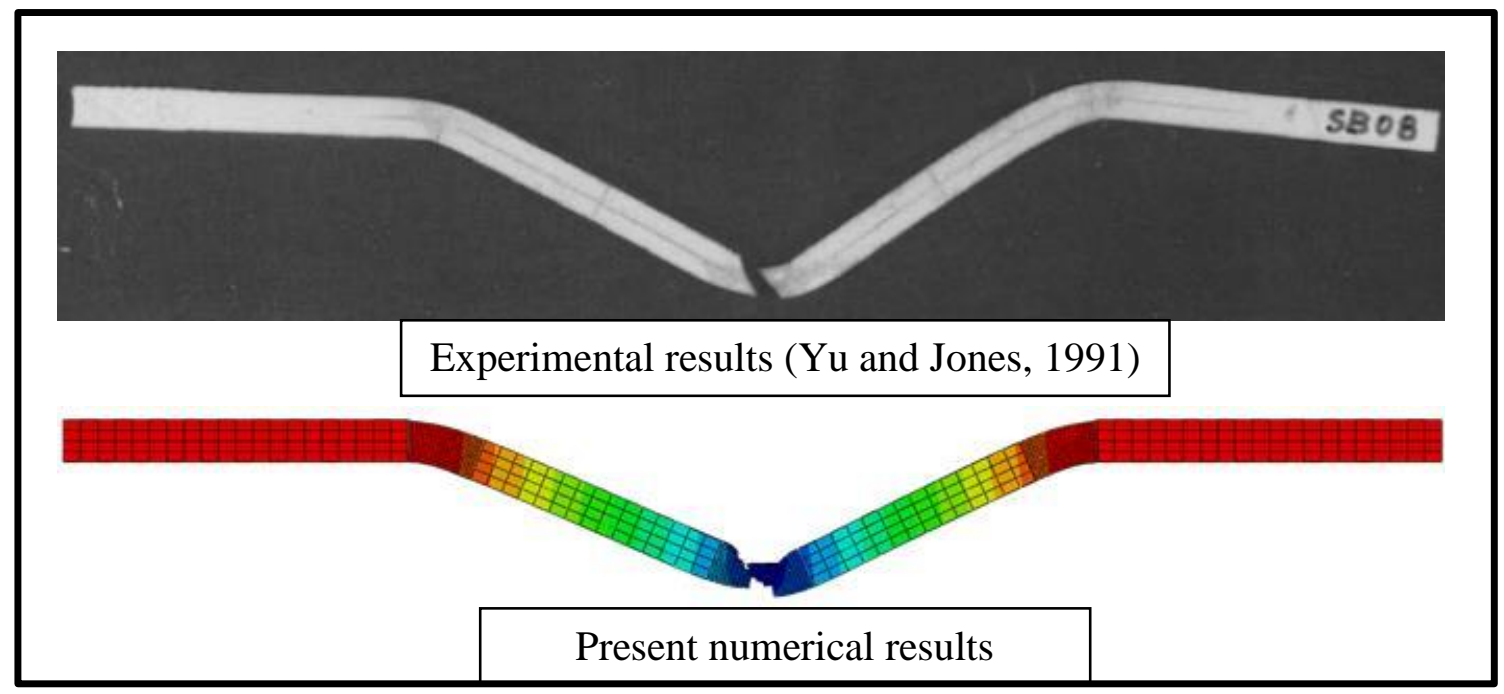

(D)

Figure 3: Experimetnal and the present numerical results for (A) the transverse displacementtime history SB07; (B) the axial strain SB08; (C) distribution of the shear damage initiation criterion along the longitudinal distance along the bottom of the beam; and (D) deformation shape and shear failure.

\subsection{Validation 3: Simulation of Global buckling failure}

The capability of the numerical model to capture the global buckling failure is validated using the experimental test conducted by Zeinoddini, Parke and Harding [19]. Un-strengthened, 1meter long CHS (circular hollow section) specimens were tested with one fixed and one sliding end subjected to a $25.54 \mathrm{~kg}$ mass with a falling velocity $7 \mathrm{~m} / \mathrm{s}$ (more detail on the experimental test is given in [19]). The specimens were tested under different compression load levels $\left(\mathrm{P} / \mathrm{P}_{\mathrm{y}}\right)$ varied between 0 to $70 \%$ as listed in Table 4. The compression load was applied using a special technique in which a disc spring pile was used to maintain the axial load during the impact.

\subsubsection{Numerical model description}

The steel member was modelled using a four-node shell element S4R, while an eight-node brick element C3D8R is adopted to model the indenter. The strain hardening and strain rate effects were accounted for in steel using isotropic strain hardening and the Cowper Symonds model respectively. The values of the modulus of elasticity and Poisson's ratio were $200 \mathrm{GPa}$ and 0.3 
respectively. The values of the yield stress and ultimate strength of the steel were 516 and 538 MPa respectively [19]. No failure criterion was defined for the steel in this simulation because no material failure occurred in the experimental tests. A linear spring was used to define the disc spring pile used in experimental. Since the ABAQUS/Explicit solver was used in this simulation the axial load was applied using a special quasi-static technique in which the load was applied during the natural period of the system by adopting a smooth step [27].

Table 4: comparison between experimental and numerical results

\begin{tabular}{|l|l|l|l|l|}
\hline \multirow{2}{*}{ P/Py(\%) } & \multicolumn{2}{|l|}{ Experimental (mm) } & Numerical (mm) \\
\cline { 2 - 5 } & Permanent deflection & Shortening & Permanent deflection & Shortening \\
\hline 0 & 15.5 & 0.3 & 17.3 & 0.4 \\
\hline 25 & 21.5 & 0.8 & 19.4 & 1.4 \\
\hline 50 & 25.3 & 2.3 & 26.6 & 3.5 \\
\hline 70 & - & 113 & 195.1 & 112 \\
\hline
\end{tabular}

\subsubsection{Validation 3 Results}

Table 4 summarises the comparison between experimental and numerical permanent deflection and axial shortening. Good agreement was achieved using the numerical model in terms of maximum deformation; shortening and deformation at failure (see Figure $4(\mathrm{~A})$ ). On the other hand, the impact load, which is the interface force developed under the indenter, recorded during the tests for different levels of axial load was compared with corresponding numerical values as shown in Figure 4 (B). It can be noticed from this figure that maximum impact load happens with a lower level of axial load while the specimen with $70 \%$ preloading level has the minimum value of impact load. This indicates the higher the pre-compression, the less stiff the response. 

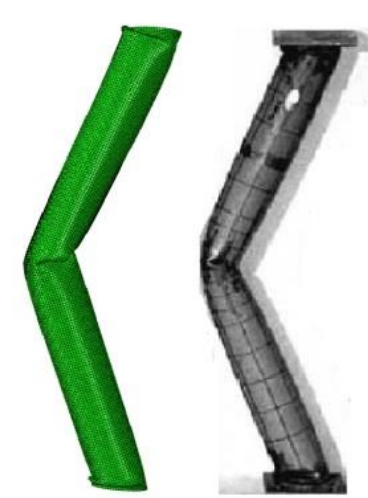

(A)

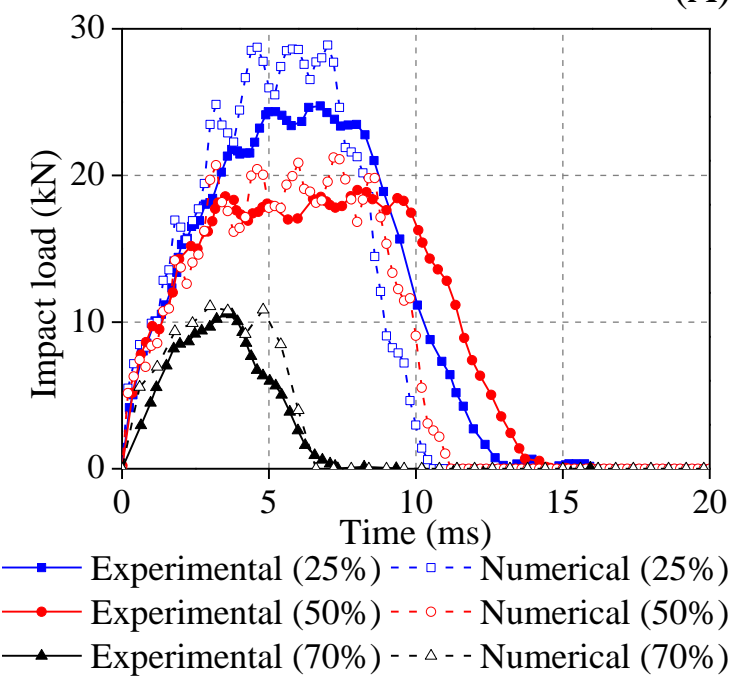

(B)
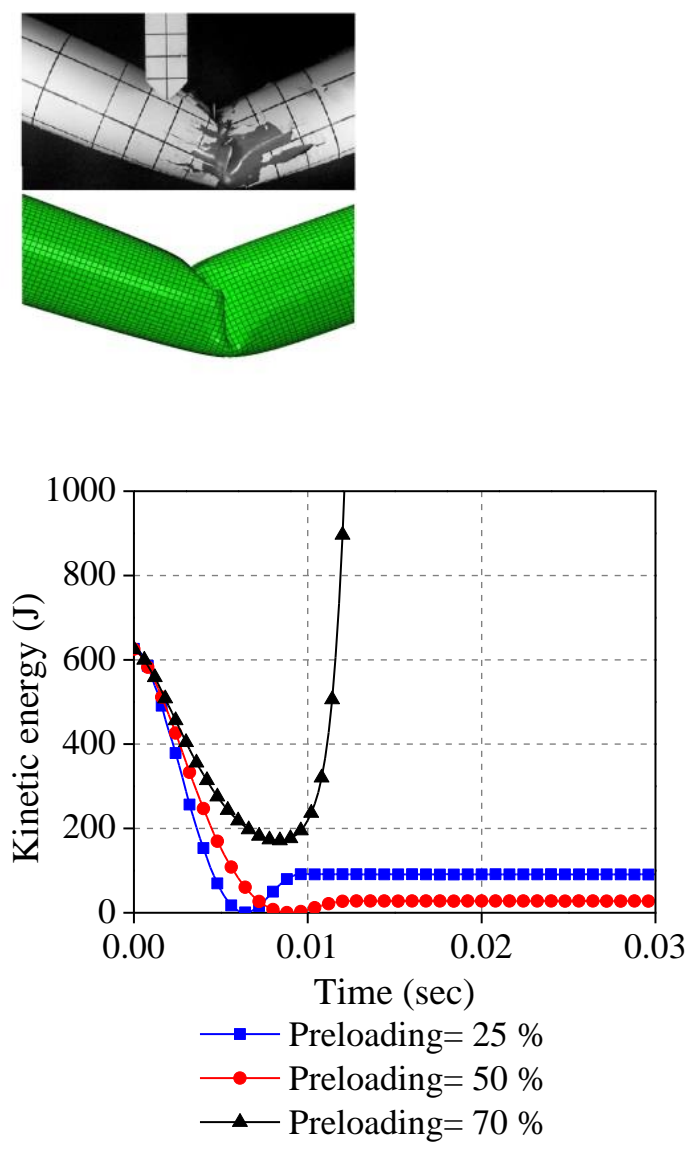

$(\mathrm{C})$

Figure 4: Comparison between experimental [19], and numerical results (A) deformation shape; (B) impact load; (C) Kinetic energy history for the columns tested under various preloading level.

In this validation study, the kinetic energy history was used as an indication of global buckling. This method was correctly employed by other researchers to capture this kind of failure [2]. The simulation results showed that the kinetic energy normally decreased until reaching zero after that there is a small rise representing the rebound energy as shown in Figure 4 (C). This trend represents the stable samples which are the samples that did not fail under the applied work including $25 \%$ and $50 \%$ preloading levels. For the failed sample (70\% preloading level), the trend seems to be different, in which the kinetic energy before being completely dissipated (reaching zero) suddenly increases indicating rapid movement (instability) of the column. The 
simulation results seem to be identical with those experimentally found by Zeinoddini, Parke and Harding [19] in terms of failure modes.

In conclusion, the three validation studies have shown that the current ABAQUS/Explicit model can adequately simulate the response of CFRP strengthened steel columns subjected to impact load and capture the key failure modes.

\section{CFRP strengthened H' section steel columns under impact load}

In order to investigate the effectiveness of CFRP in strengthening open-section steel columns under impact loads, a full-scale column section $3.5 \mathrm{~m}$ long was designed according to Eurocode 3 [21] to carry a load consistent with a six storey commercial building. The designed column (UC $305 \times 305 \times 97$ ) was assumed to be an interior ground floor column where columns were spaced at $7.5 \mathrm{~m}$ centres. The steel was assumed to be of grade $\mathrm{S} 275$ a yield strength of $275 \mathrm{MPa}$ and an ultimate strength of $500 \mathrm{MPa}$ (with a corresponding plastic strain of 0.2 ). The steel density and the modulus of elasticity were $7850 \mathrm{~kg} / \mathrm{m}^{3}$ and $205 \mathrm{GPa}$ respectively. The properties of CFRP and adhesive material used in these simulations were the same for those reported in Kadhim, Wu and Cunningham [17] as listed in Table 1 and Table 2.

\subsection{Numerical modelling}

The Solid element provided by ABAQUS/Explicit with reduced integration and hourglass control (C3D8R) was adopted to model the steel and impactor in this simulation. The CFRP and adhesive material were modelled as described in the validation studies. From the mesh sensitivity study, it was found that dividing the web and flange of the column into 12 and 14 divisions gave reasonable results when compared to those having a finer mesh. In addition, in the axial direction of the column, changing the mesh size had a minor effect when choosing an element length finer 
than $20 \mathrm{~mm}$. Thus, the above mesh size was chosen for all of the further simulations in this study. Moreover, the element length for the CFRP and adhesive material was chosen to be the same for the steel column because the further reduction in the mesh size did not have a discernible effect on the results.

The Cowper-Symonds model was employed to include the strain rate effect with material parameters of $\mathrm{D}=40.4 \mathrm{sec}^{-1}$ and $\mathrm{q}=5$ [22]. The progressive damage model was employed to account for the possibility of any development of shear failure in the steel column. The parameters used to introduce the shear progressive damage in the steel are presented in Table 3. These parameters were chosen depending on the material properties of S275 steel and a finite element analysis carried out before this simulation. Tensile tearing failure was not included in this simulation as mentioned earlier since the focus is on columns with free axial movement.

The impacting body was assumed to be a rigid body and the impact energy would be totally absorbed by the structural member without any contribution from the impactor. The modulus of elasticity of the impactor was selected carefully such that it behaves as a rigid body. In addition, the density of impactor was changed based on the required mass. The dimensions of the impactor were set as $1 \mathrm{~m}$ long with a $0.1 \mathrm{~m} \times 0.1 \mathrm{~m}$ cross section.

\subsection{CFRP configurations}

In order to investigate strengthening effectiveness, three different CFRP configurations were examined as shown in Figure 5. In all these configurations, the steel column was strengthened with fibres of the composite oriented in the longitudinal direction (parallel to the direction of the axial compressive load). In addition, the thickness of the CFRP was kept constant (5 $\mathrm{mm})$ in all configurations, the effect of varying plate thickness is studied later in a separate parametric study. Where used, the CFRP was applied along the full height of the column. 


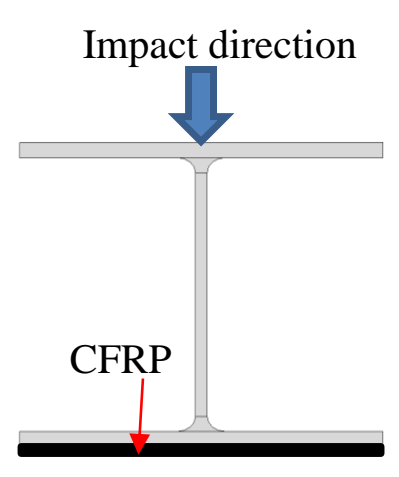

F1

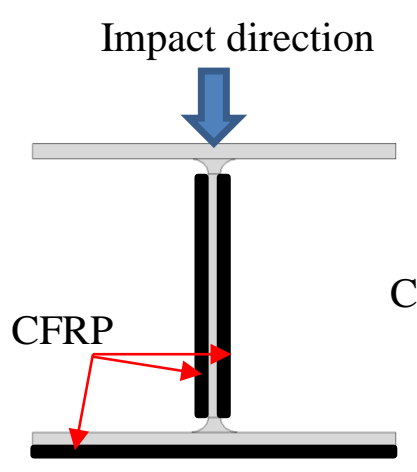

F2

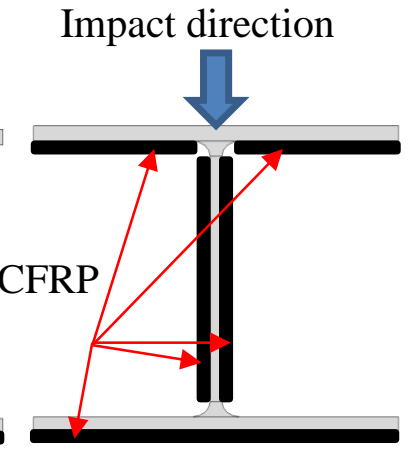

F3

Figure 5: Plan view of $\mathrm{H}$-sections showing CFRP configurations.

\subsection{Kinetic energy}

The mass of the impacting body and its velocity is selected carefully to represent a real life case. One of the most common sources of impact events in a frame building is vehicle impact and this source will be adopted in this study. Among eight different types (typical cars and light trucks) the range of the vehicle masses was found to be between $1100 \mathrm{~kg}$ and $3054 \mathrm{~kg}$ [28]. Thus, two masses namely $1000 \mathrm{~kg}$ and $3000 \mathrm{~kg}$ were chosen as being those of a typical car and a light truck. Eurocode 1 [29] gives the design values for vehicle velocity that should be used to design structural elements against vehicle impact depending on the location of the structure, these being 90, 50, 20 and $10 \mathrm{~km} / \mathrm{hr}$ for motorways, urban areas, courtyards and parking garages respectively. Among these vehicle velocities, 20 and $50 \mathrm{~km} / \mathrm{hr}$ were chosen here.

The impact location (height) can vary between 0.5 and $1.5 \mathrm{~m}$ from the bottom of the column as recommended by Eurocode 1 [29], therefore both of these locations will be considered in this study. In addition, different preloading levels including $0,25,50,75$ and $100 \%$ (the ratio between the applied compressive load to the design load of the un-strengthened column) were

examined in this simulation. The impact direction was assumed to be on the major (strong) axis of the column. However, impact from other directions will separately be investigated later in the parametric study. Finally, among various possible supporting conditions two boundary 
conditions were investigated. Boundary condition $1(\mathrm{BC} 1)$ is whereby the base of the column is pinned in each direction, while the top is pinned horizontally and free to move vertically. For boundary condition 2 (BC2), the base of the column is fully fixed while the top is pinned horizontally and free to move vertically.

\section{Configuration Study Results}

The main focus in this section will be to demonstrate the capability of the CFRP to reduce transverse displacement and prevent the failure of the transversely impacted column as an indication of level of strengthening achieved. Regarding the failure modes, the focus will be on modes that cause full collapse including global buckling and transverse shear failure, while in the case of a CFRP strengthened column exhibiting a different kind of failure pattern such as debonding, CFRP rupture and local deformation, this will not be considered as a failed column.

\subsection{Columns with Boundary Condition 1 (BC1)}

Here the boundary condition at the column base was pinned in each direction, whereas the top is pinned horizontally and free to move vertically. Table 5 summarises the failure modes for the strengthened and un-strengthened columns that were struck by a $1000 \mathrm{~kg}$ and $3000 \mathrm{~kg}$ mass respectively (note $\mathrm{U}$ denotes un-strengthened). Generally, global buckling failure predominated. It can be noticed from these tables that the strengthened columns showed superior performance by preventing global buckling failure in many cases. In particular, the strengthening configurations F2 and F3 can prevent failure in most cases for all kinetic energy values except for the $289 \mathrm{~kJ}$ case where the CFRP can only stop the failure of the columns without preloading. It should be pointed out that the stable situation in this study refers to the fact that no global buckling or shear failure occurs in the column regardless of other types of failure because if other 
types of failure occurred (as elucidated at the beginning of this section), the column should still be able to carry the applied work.

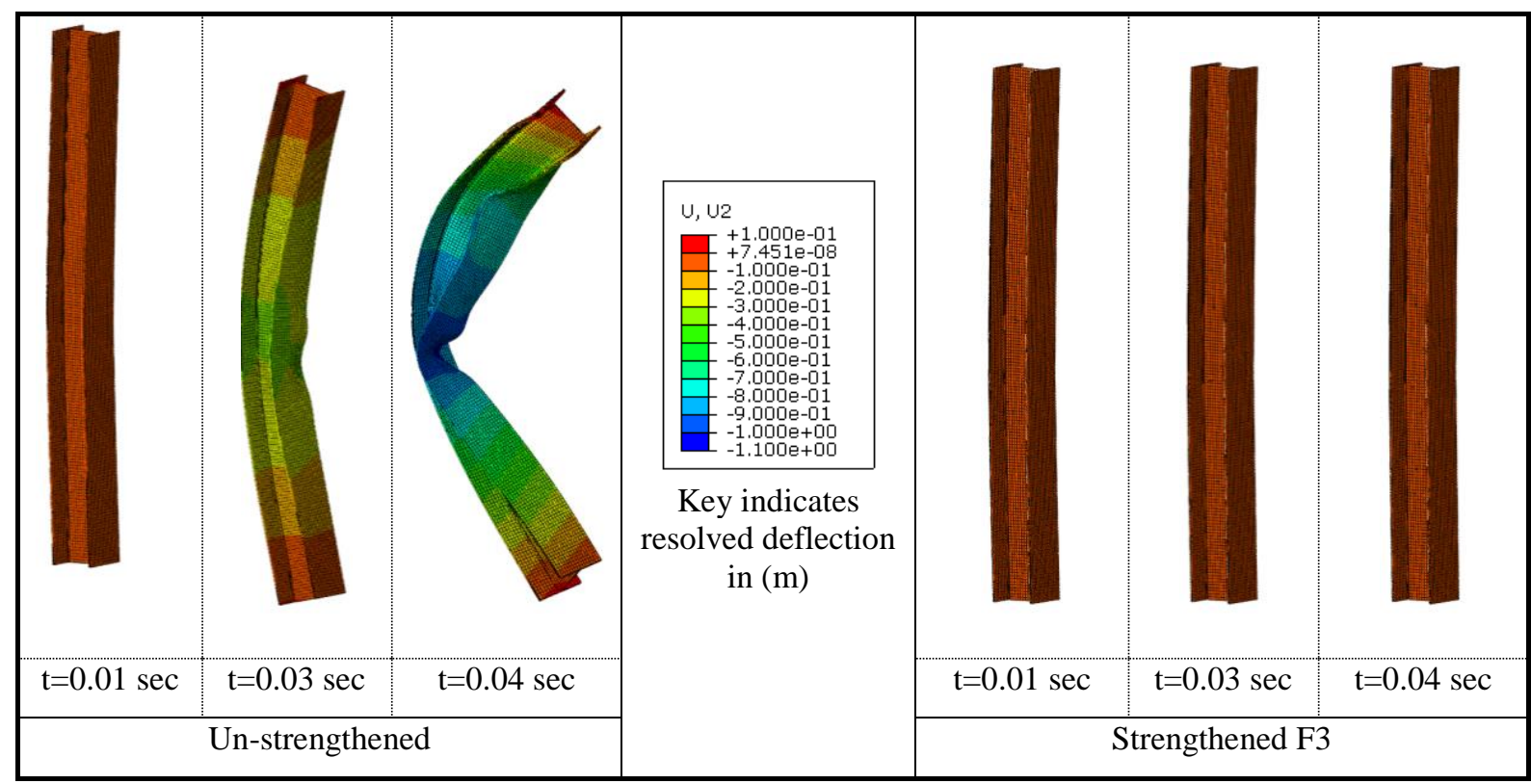

(A)

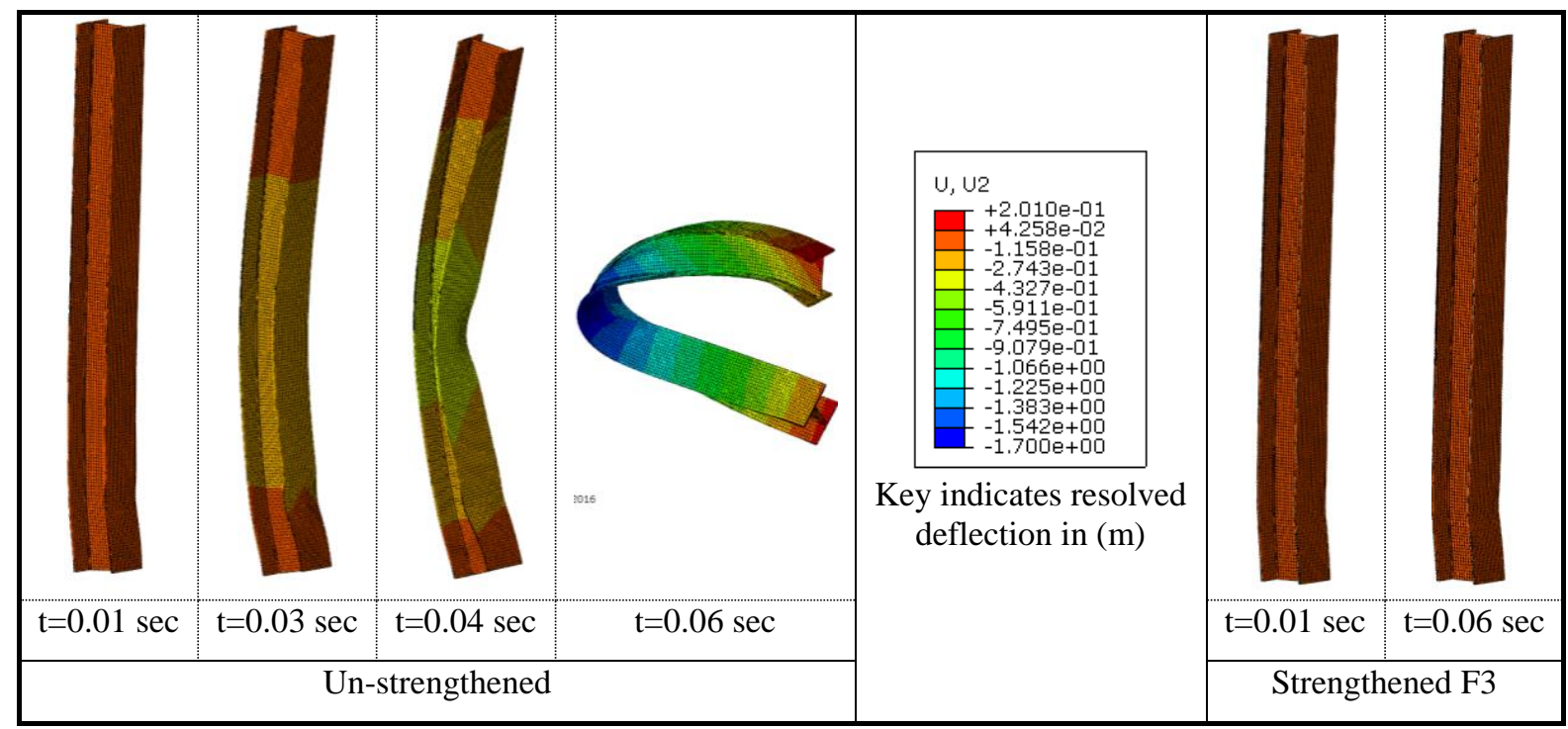

(B) 


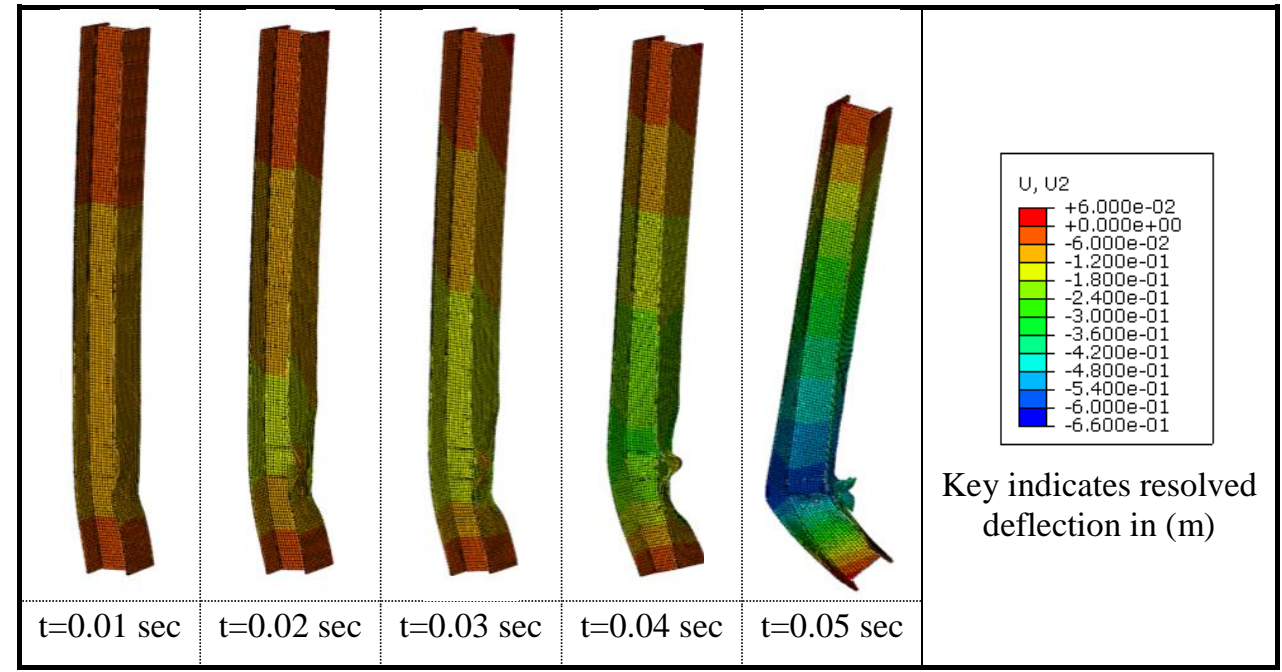

(C)

Figure 6 illustrates comparisons between strengthened and un-strengthened columns struck with two different kinetic energies, impact heights and preloading levels to reflect the capability of the CFRP in preventing the global failure of the column.

The location of the intermediate plastic hinge was found to be approximately at the mid-height of the un-strengthened column regardless of the impact location when the preloading level was more than $25 \%$ as shown in

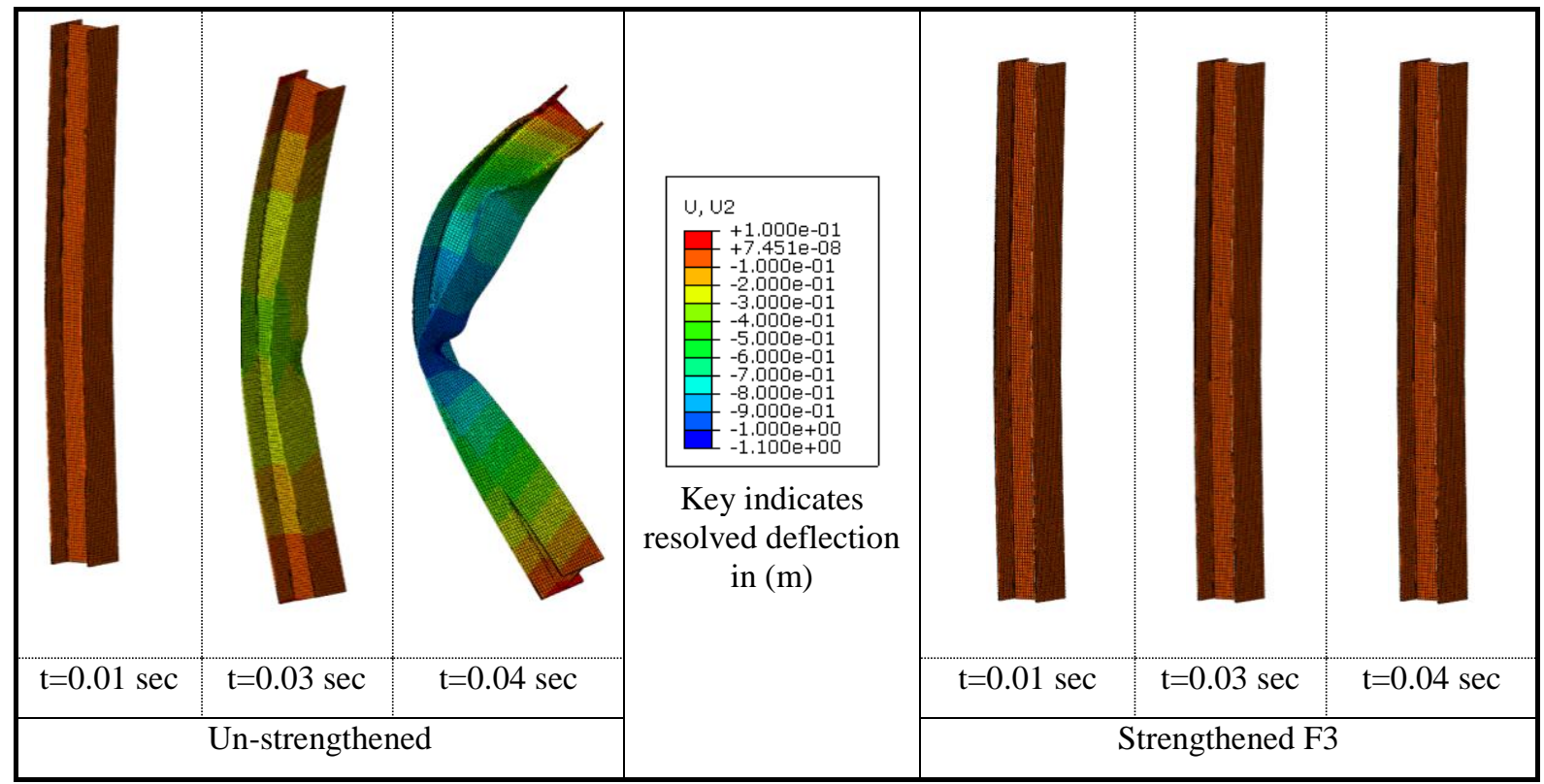

(A) 


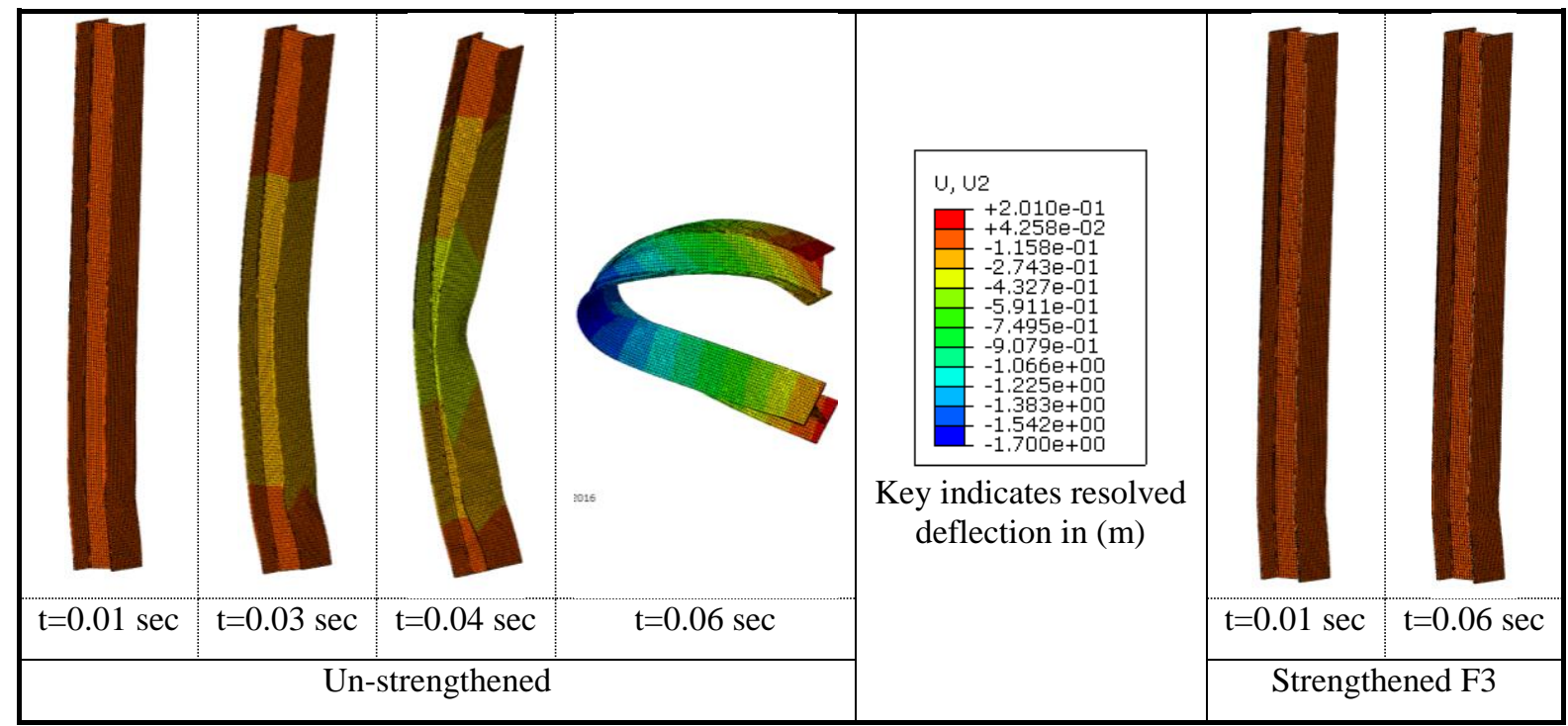

(B)

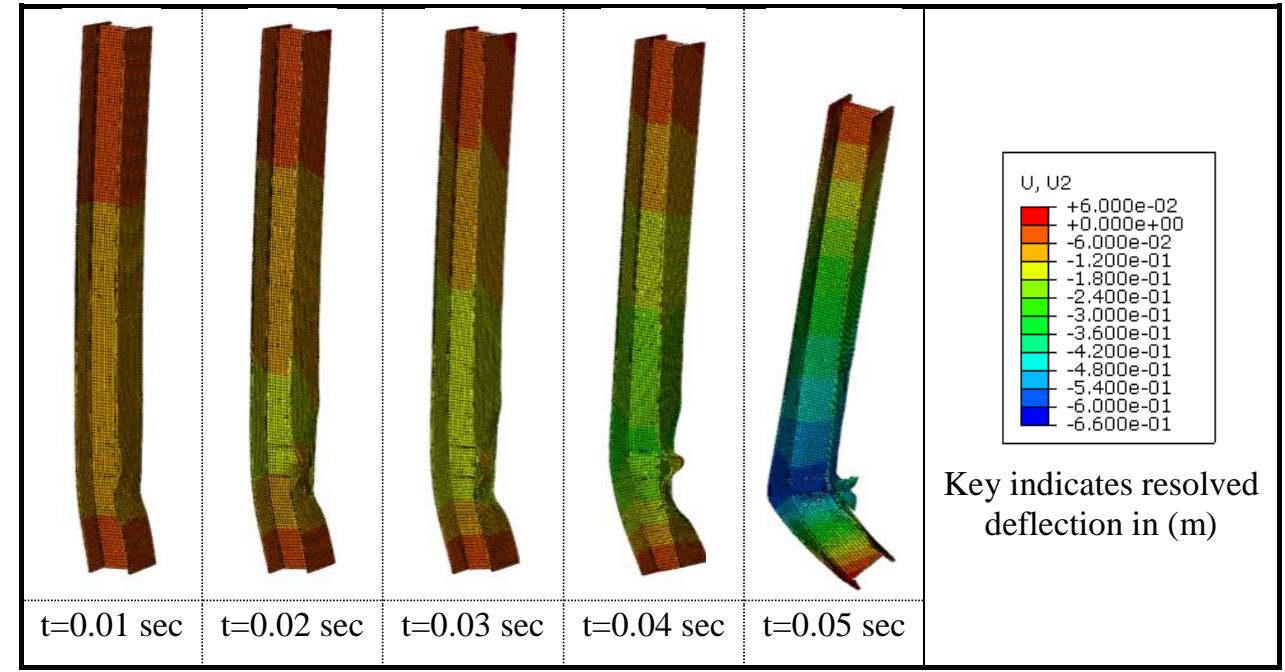

(C)

Figure 6(A) and (B). Similar trends were also observed by other researchers [28] who investigated the impact response of un-strengthened I-section steel columns. This is because when the column fails due to global buckling, the deformed shape of the column is expected to follow the first mode of static buckling $[28,30]$. However, the strengthened columns exhibited a different failure mode in which the location of the plastic hinge was approximately at the impact location regardless of the preloading level as shown in 


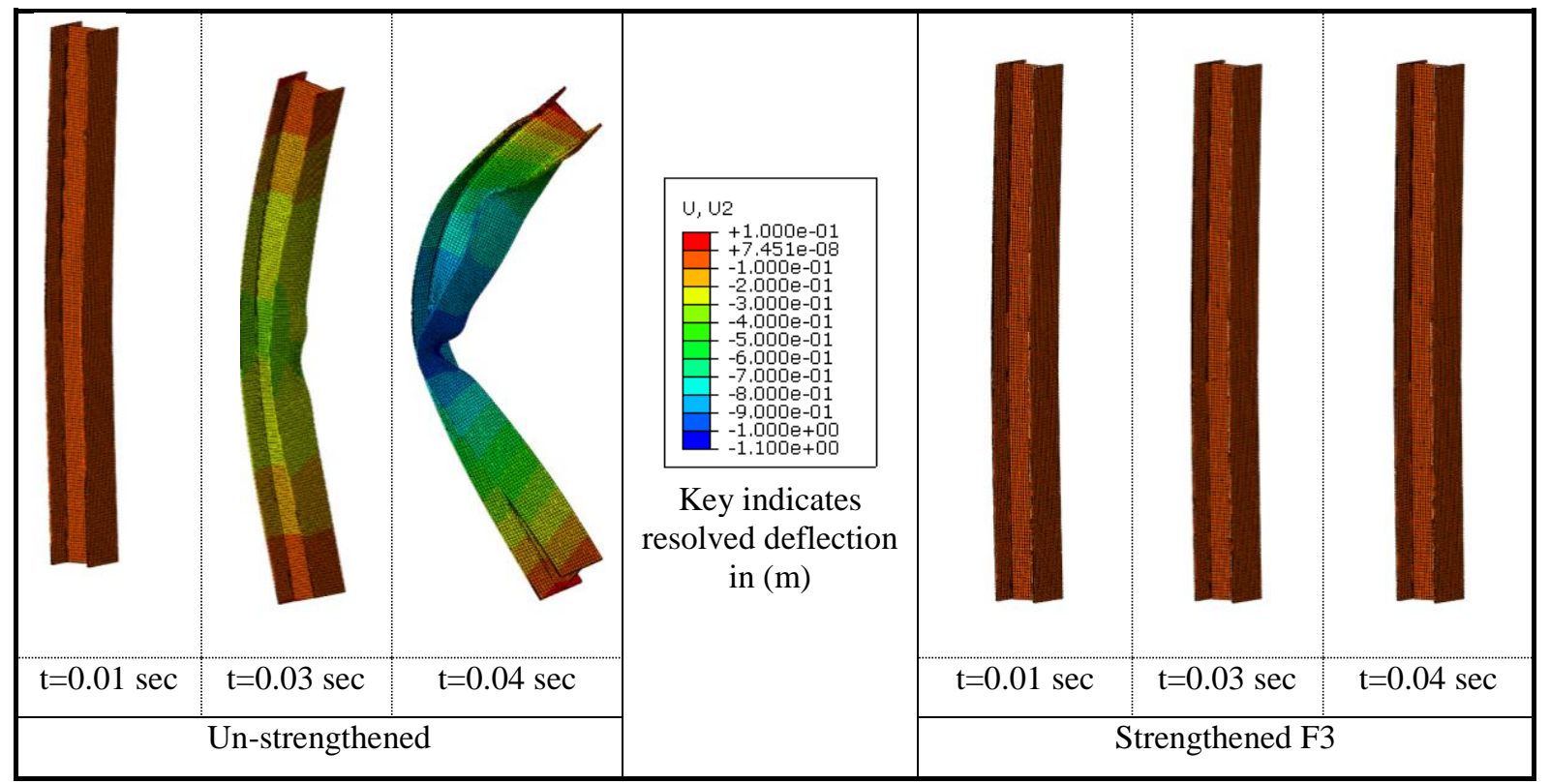

(A)

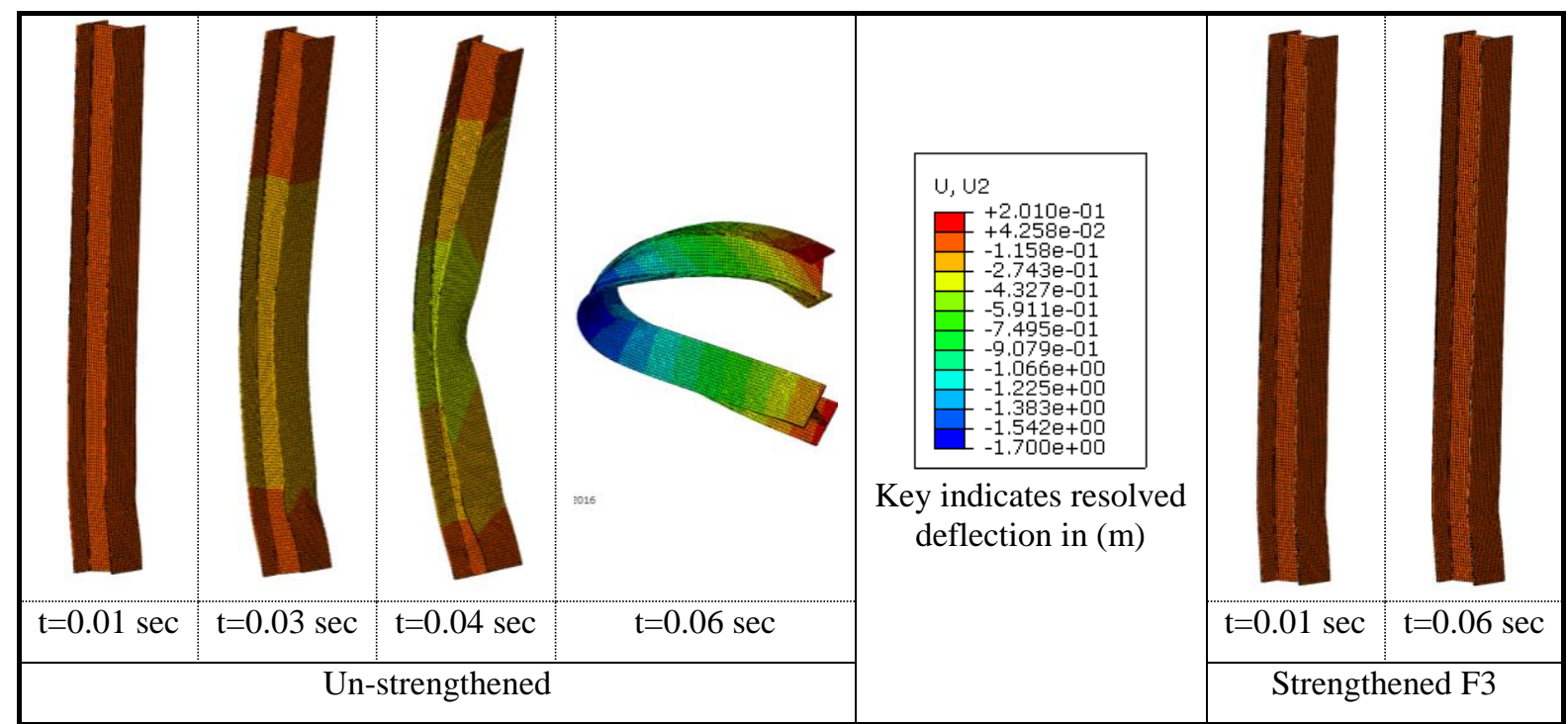

(B)

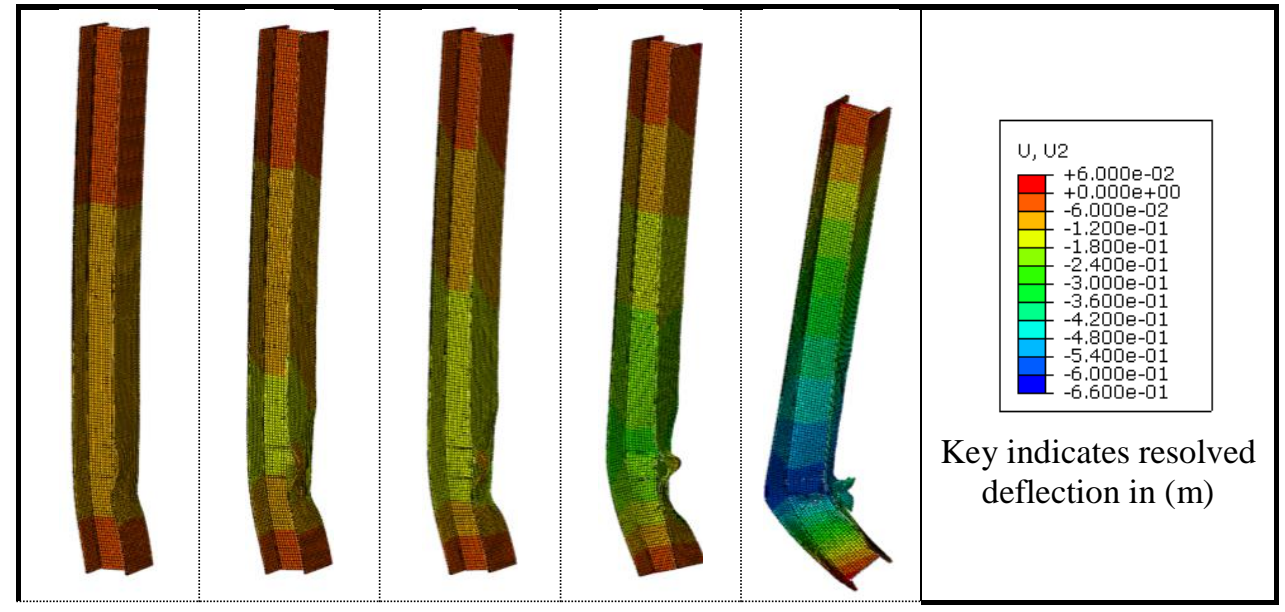




\section{$t=0.01 \mathrm{sec} \quad t=0.02 \mathrm{sec} t=0.03 \mathrm{sec} \quad t=0.04 \mathrm{sec} \quad t=0.05 \mathrm{sec}$}

(C)

Figure 6(C). This may be caused by the fact that most of the strengthened columns when impacted by a high kinetic energy incurred a local CFRP failure in the impact region which makes this region a weak point, while the CFRP in other locations did not exhibit any kind of failure.

Table 5: Failure modes of BCl columns struck with a 1000 and $3000 \mathrm{~kg}$ mass.

\begin{tabular}{|c|c|c|c|c|c|c|c|c|c|c|c|c|c|c|c|c|}
\hline \multicolumn{17}{|c|}{ Impactor mass $=1000 \mathrm{~kg}$} \\
\hline \multirow{4}{*}{ 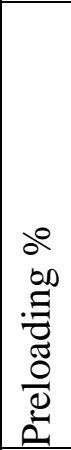 } & \multicolumn{8}{|c|}{ Impact velocity $=20 \mathrm{~km} / \mathrm{hr}(\mathrm{KE}=15.4 \mathrm{~kJ})$} & \multicolumn{8}{|c|}{ Impact velocity $=50 \mathrm{~km} / \mathrm{hr}(\mathrm{KE}=96.4 \mathrm{~kJ})$} \\
\hline & \multicolumn{2}{|l|}{$\mathrm{U}$} & \multicolumn{2}{|c|}{ F1 } & \multicolumn{2}{|l|}{$\mathrm{F} 2$} & \multicolumn{2}{|c|}{$\mathrm{F} 3$} & \multicolumn{2}{|l|}{$\mathrm{U}$} & \multicolumn{2}{|l|}{$\mathrm{F} 1$} & \multicolumn{2}{|l|}{$\mathrm{F} 2$} & \multicolumn{2}{|l|}{ F3 } \\
\hline & \multicolumn{2}{|c|}{$\begin{array}{l}\text { Height } \\
\text { (m) }\end{array}$} & \multicolumn{2}{|c|}{$\begin{array}{l}\text { Height } \\
\text { (m) }\end{array}$} & \multicolumn{2}{|c|}{$\begin{array}{l}\text { Height } \\
\text { (m) }\end{array}$} & \multicolumn{2}{|c|}{$\begin{array}{l}\text { Height } \\
\text { (m) }\end{array}$} & \multicolumn{2}{|c|}{$\begin{array}{l}\text { Height } \\
\text { (m) }\end{array}$} & \multicolumn{2}{|c|}{$\begin{array}{l}\text { Height } \\
\text { (m) }\end{array}$} & \multicolumn{2}{|c|}{$\begin{array}{l}\text { Height } \\
\text { (m) }\end{array}$} & \multicolumn{2}{|c|}{$\begin{array}{l}\text { Height } \\
\text { (m) }\end{array}$} \\
\hline & $\begin{array}{l}0 . \\
5\end{array}$ & $\begin{array}{l}1 . \\
5\end{array}$ & $\begin{array}{l}0 . \\
5\end{array}$ & 1.5 & 0.5 & $\begin{array}{l}1 . \\
5\end{array}$ & $\begin{array}{l}0 . \\
5\end{array}$ & $\begin{array}{l}1 . \\
5\end{array}$ & 0.5 & $\begin{array}{l}1 . \\
5\end{array}$ & 0.5 & $\begin{array}{l}1 . \\
5\end{array}$ & 0.5 & 1.5 & $\begin{array}{l}0 . \\
5\end{array}$ & 1.5 \\
\hline 0 & $\mathrm{~S}$ & S & $\mathrm{S}$ & $\mathrm{S}$ & $S$ & $\mathrm{~S}$ & $\mathrm{~S}$ & $\mathrm{~S}$ & $S$ & $\mathrm{~S}$ & $\mathrm{~S}$ & $\mathrm{~S}$ & $\mathrm{~S}$ & $S$ & $\mathrm{~S}$ & $\mathrm{~S}$ \\
\hline 25 & $\mathrm{~S}$ & $\mathrm{~S}$ & $\mathrm{~S}$ & $\mathrm{~S}$ & S & $\mathrm{S}$ & $\mathrm{S}$ & $\mathrm{S}$ & $S$ & $\mathrm{~S}$ & $S$ & $\mathrm{~S}$ & $\mathrm{~S}$ & $S$ & $S$ & $S$ \\
\hline 50 & $S$ & $S$ & $S$ & $S$ & $S$ & $S$ & $\mathrm{~S}$ & $S$ & $\mathrm{G}$ & G & $G$ & $\mathrm{G}$ & $S$ & $S$ & $S$ & $\mathrm{~S}$ \\
\hline 75 & $S$ & $S$ & $S$ & $\mathrm{~S}$ & $S$ & $\mathrm{~S}$ & $\mathrm{~S}$ & $\mathrm{~S}$ & $\mathrm{G}$ & $\mathrm{G}$ & $\mathrm{G}$ & $\mathrm{G}$ & $\mathrm{S}$ & $\mathrm{G}$ & $S$ & $\mathrm{G}$ \\
\hline 10 & $\mathrm{G}$ & $\mathrm{G}$ & G & $\mathrm{G}$ & $S$ & S & $\mathrm{S}$ & $\mathrm{S}$ & G & G & $\mathrm{G}$ & $\mathrm{G}$ & G & $\mathrm{G}$ & $\mathrm{G}$ & G \\
\hline \multicolumn{17}{|c|}{ Impactor mass $=3000 \mathrm{~kg}$} \\
\hline \multirow{4}{*}{ 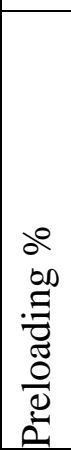 } & \multicolumn{8}{|c|}{ Impact velocity $=20 \mathrm{~km} / \mathrm{hr}(\mathrm{KE}=46.3 \mathrm{~kJ}$} & \multicolumn{8}{|c|}{ Impact velocity $=50 \mathrm{~km} / \mathrm{hr}(\mathrm{KE}=289 \mathrm{~kJ})$} \\
\hline & \multicolumn{2}{|l|}{$\mathrm{U}$} & \multicolumn{2}{|c|}{$\mathrm{F} 1$} & \multicolumn{2}{|l|}{$\mathrm{F} 2$} & \multicolumn{2}{|c|}{ F3 } & \multicolumn{2}{|l|}{$\mathrm{U}$} & \multicolumn{2}{|l|}{$\mathrm{F} 1$} & \multicolumn{2}{|l|}{$\mathrm{F} 2$} & \multicolumn{2}{|c|}{ F3 } \\
\hline & \multicolumn{2}{|c|}{$\begin{array}{l}\text { Height } \\
\text { (m) }\end{array}$} & $\mathrm{H}$ & & $\begin{array}{l}\text { Hei } \\
\text { (m) }\end{array}$ & & $\mathrm{H}$ & & $\begin{array}{l}\mathrm{Hei} \\
\text { (m) }\end{array}$ & & $\begin{array}{l}\mathrm{Hei} \\
\text { (m) }\end{array}$ & & $\begin{array}{l}\text { Hei } \\
\text { (m) }\end{array}$ & & $\mathrm{He}$ & \\
\hline & $\begin{array}{l}0 . \\
5\end{array}$ & $\begin{array}{l}1 . \\
5\end{array}$ & 0 . & 1.5 & 0.5 & 1. & 0 . & 1. & 0.5 & $\begin{array}{l}1 . \\
5\end{array}$ & 0.5 & $\begin{array}{l}1 . \\
5\end{array}$ & 0.5 & 1.5 & $\begin{array}{l}0 . \\
5\end{array}$ & 1.5 \\
\hline 0 & $\mathrm{~S}$ & $\mathrm{~S}$ & $\mathrm{~S}$ & $\mathrm{~S}$ & $\mathrm{~S}$ & $\mathrm{~S}$ & $\mathrm{~S}$ & $\mathrm{~S}$ & $S$ & $\mathrm{G}$ & $\mathrm{S}$ & $\mathrm{G}$ & $\mathrm{S}$ & $\mathrm{S}$ & S & $\mathrm{S}$ \\
\hline
\end{tabular}




\begin{tabular}{|l|l|l|l|l|l|l|l|l|l|l|l|l|l|l|l|l|}
\hline 25 & S & S & S & S & S & S & S & S & G & G & G & G & G & G & G & G \\
\hline 50 & S & S & S & S & S & S & S & S & & & & & & & & \\
\hline 75 & G & G & G & G & S & S & S & S & & & & & & & & \\
\hline $\begin{array}{l}10 \\
0\end{array}$ & G & G & G & G & G & G & S & S & & & & & & & & \\
\hline
\end{tabular}

G: global buckling failure and S: stable 


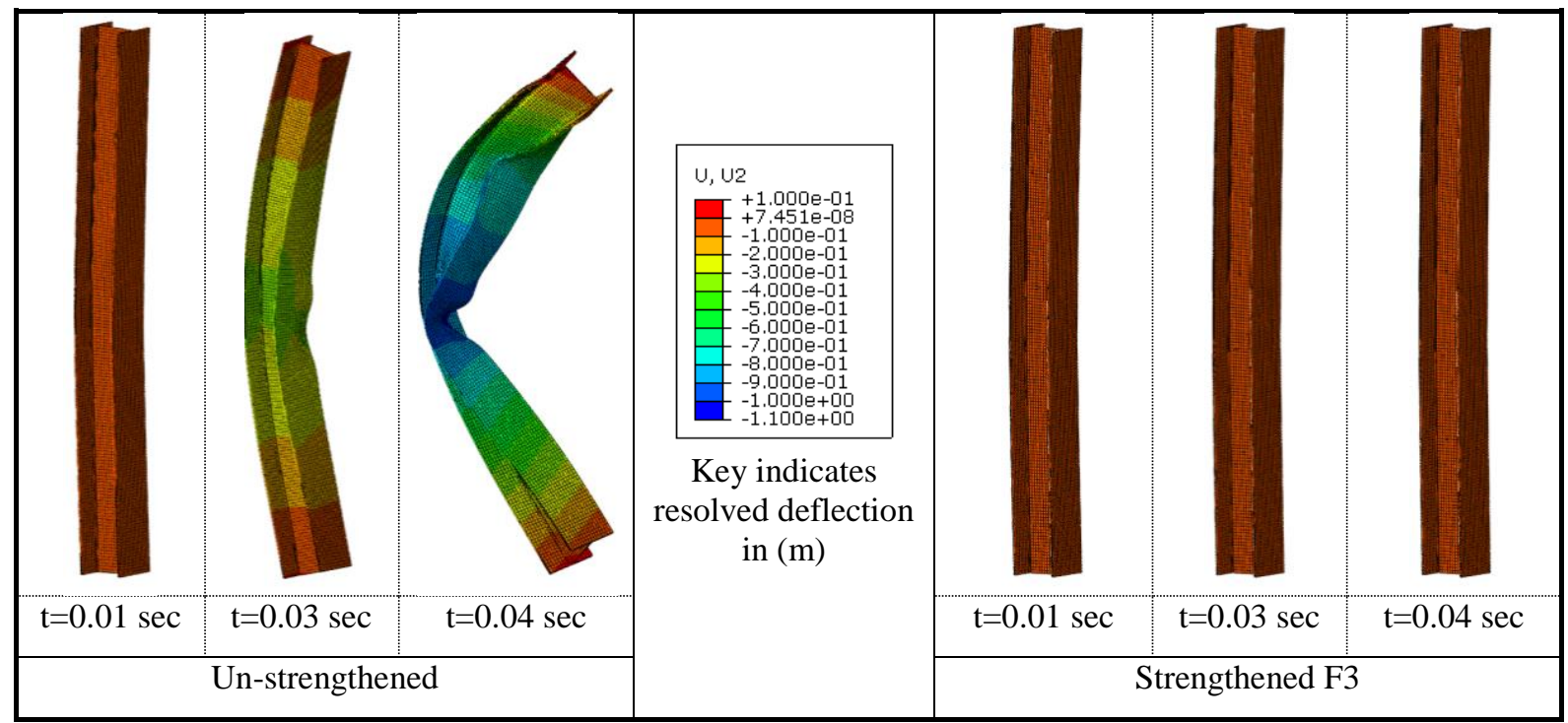

(A)

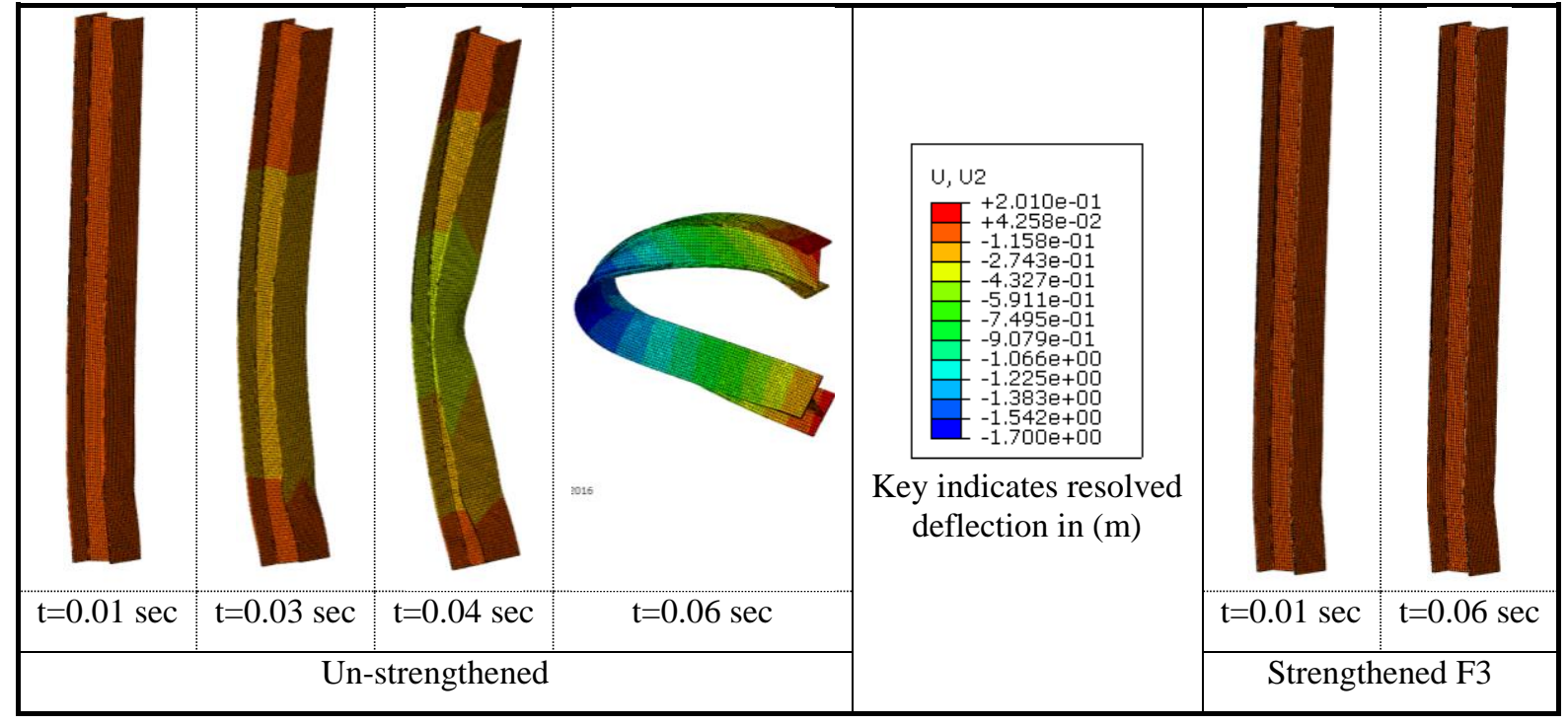

(B)

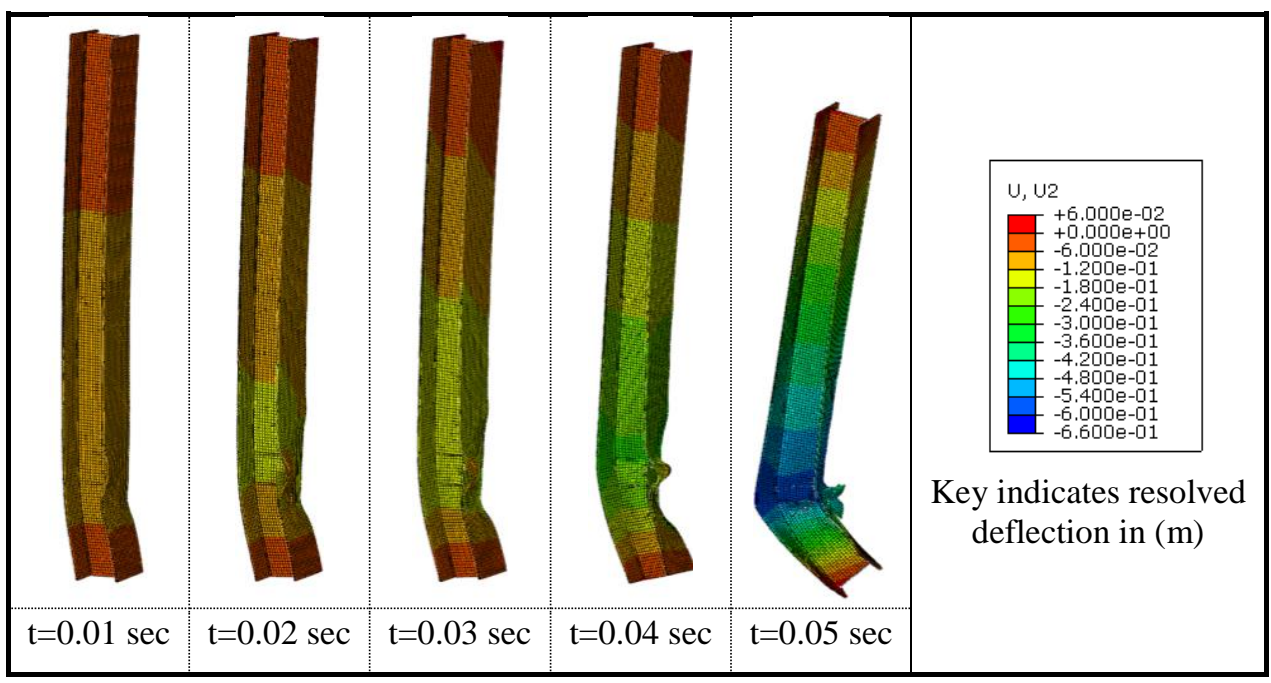

(C) 
Figure 6: Deformed shape history for the BC1 columns, (A) kinetic energy $=15.4 \mathrm{~kJ}$, impact height $=1.5 \mathrm{~m}$, preloading level $=100 \%$; $(\mathrm{B})$ and kinetic energy $=46.3 \mathrm{~kJ}$, impact height $=0.5 \mathrm{~m}$, preloading level $=75 \%$ and, $(\mathrm{C})$ strengthened column $(\mathrm{F} 3)$, kinetic energy $=96.4 \mathrm{~kJ}$, impact height $=0.5 \mathrm{~m}$ and preloading level $=100 \%$. (All deformations having the same scale)

In terms of the transverse displacement, the strengthened columns consistently had less displacement than the un-strengthened column as shown in Figure 7. It can be seen from Figure 7(A), which shows the transverse displacement of the columns analysed under $75 \%$ preloading, that the maximum transverse displacement for strengthened columns F2 and F3 was reduced by 55 and $66 \%$ in comparison with the corresponding value of the un-strengthened column. However, the strengthening configuration F1 did not show a clear reduction in the transverse displacement. In the case of $100 \%$ preloading, Figure $7(\mathrm{~B})$ illustrates that the transverse displacement for strengthened column F3 was less than $0.05 \mathrm{~m}$ while the un-strengthened column failed under the same preloading level and kinetic energy, which reflects the good performance of the strengthened columns. Similarly, when the impact height was $0.5 \mathrm{~m}$ the trend seems to be identical with that discussed above as shown in Figure 7(C) and (D). Furthermore, the comparison of the axial displacement demonstrates a similar trend to that discussed for the transverse displacement history. For example, the reduction in the maximum axial displacement for strengthened columns F2 and F3 simulated under 75\% preloading was 64 and $76 \%$ compared to the corresponding value of the un-strengthened column as shown in Figure 8. 


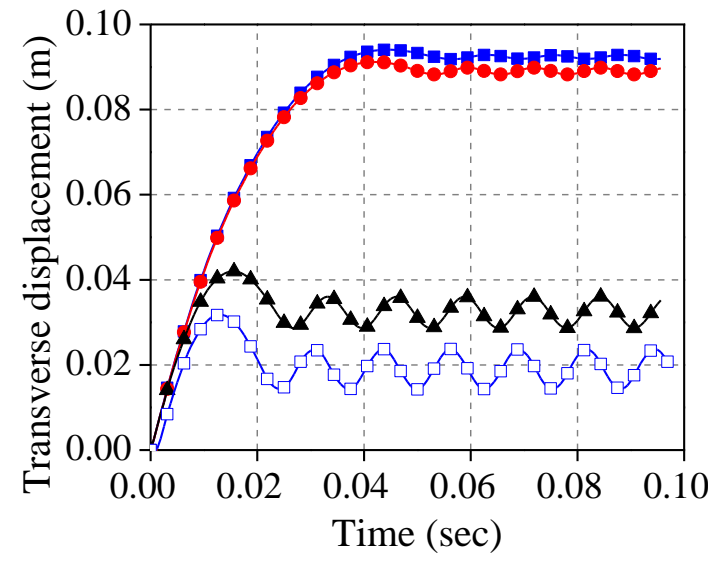

(A) Preloading 75\%, impact height $=1.5 \mathrm{~m}$

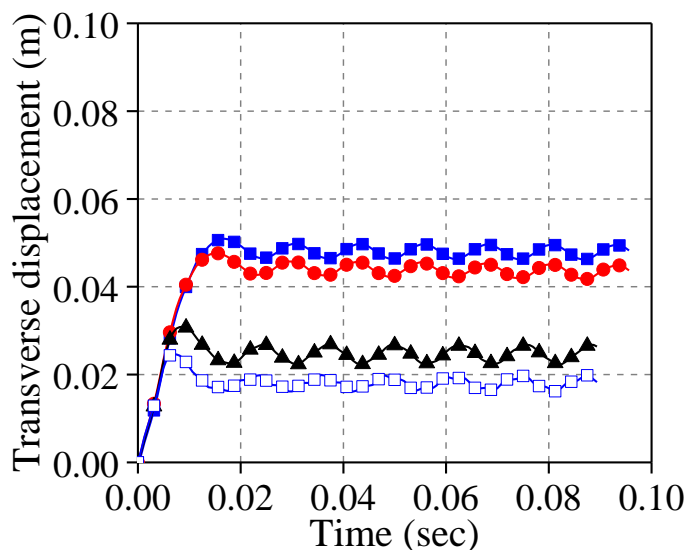

(C) Preloading 75\%, impact height $=0.5 \mathrm{~m}$

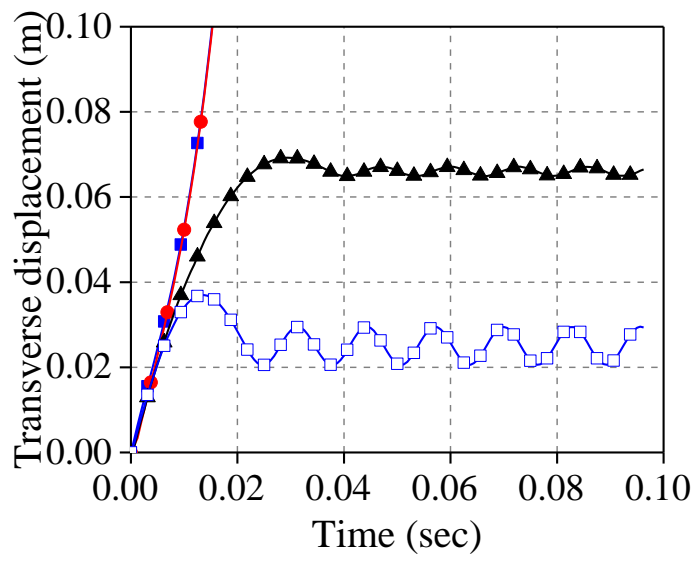

(B) Preloading $100 \%$, impact height $=1.5 \mathrm{~m}$

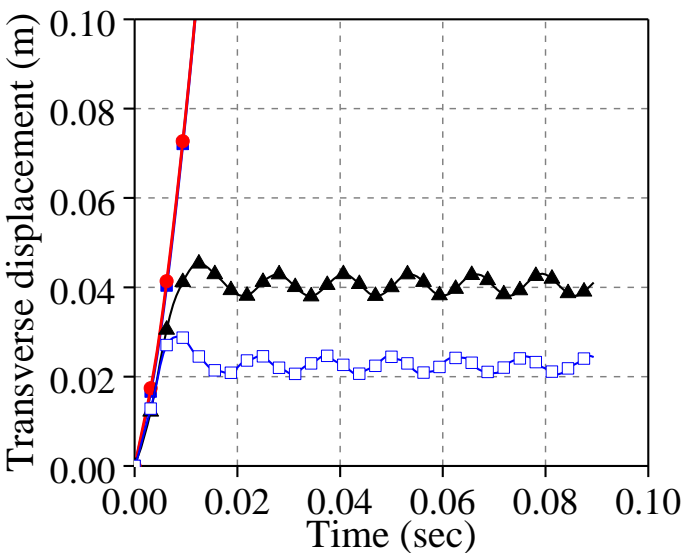

(D) Preloading $100 \%$, impact height $=0.5 \mathrm{~m}$

$\longrightarrow$ Unstrengthened $\longrightarrow$ Strengthened $\mathrm{F} 1 \longrightarrow$ Strengthened F2 $\longrightarrow$ Strengthened F3

Figure 7: Transverse displacement histories for BC1 columns (kinetic energy $=15.4 \mathrm{~kJ}$ ).

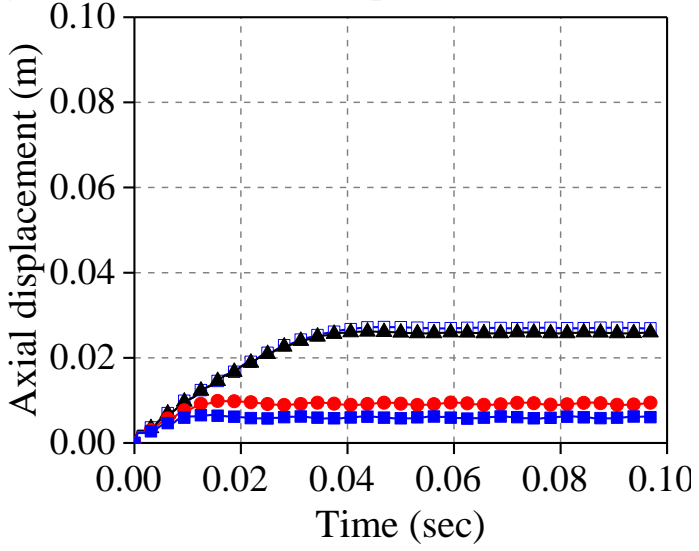

(A) Preloading 75\%

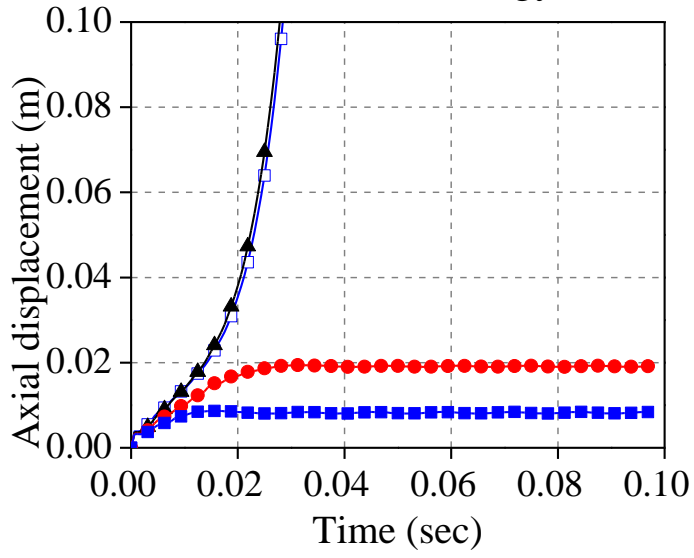

(B) Preloading 100\%

$\longrightarrow$ Unstrengthened $\longrightarrow$ Strengthened F1 $\longrightarrow$ Strengthened F2 $\square$ Strengthened F3

Figure 8: $\mathrm{BC} 1$ columns, Axial displacement histories (kinetic energy= $15.4 \mathrm{~kJ}$, impact height= $1.5 \mathrm{~m})$.

This general trend seems to be the same for all preloading levels and kinetic energies simulated in this section. For example, Figure 9 shows that the effectiveness of the CFRP increased with 
the high preloading levels. Similarly, the higher the kinetic energy, the higher the strengthening effectiveness. It must be mentioned here that in many cases the CFRP in the strengthened column exhibited some localised ruptures in the CFRP layers without an effect on the global behaviour of the column as a result of the rupture.

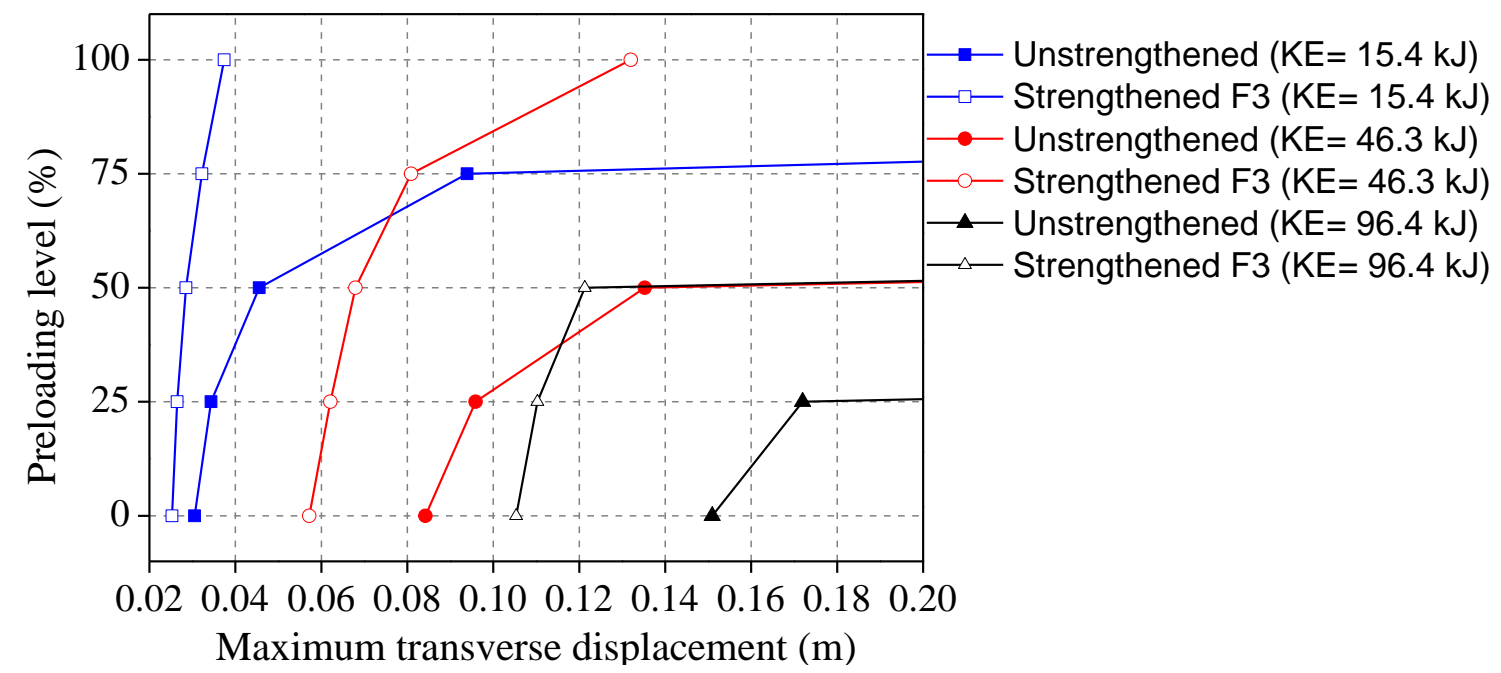

Figure 9: Comparison of Maximum transverse displacement against preloading between the unstrengthened and strengthened columns (F3) columns for different kinetic energy.

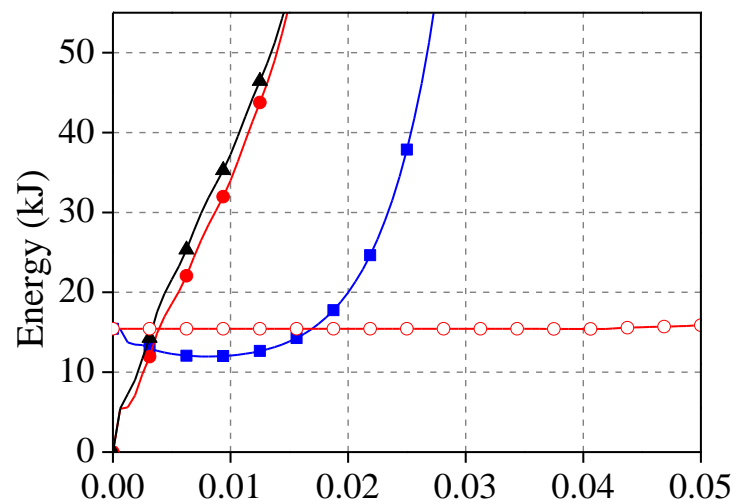

(A) Time (sec)

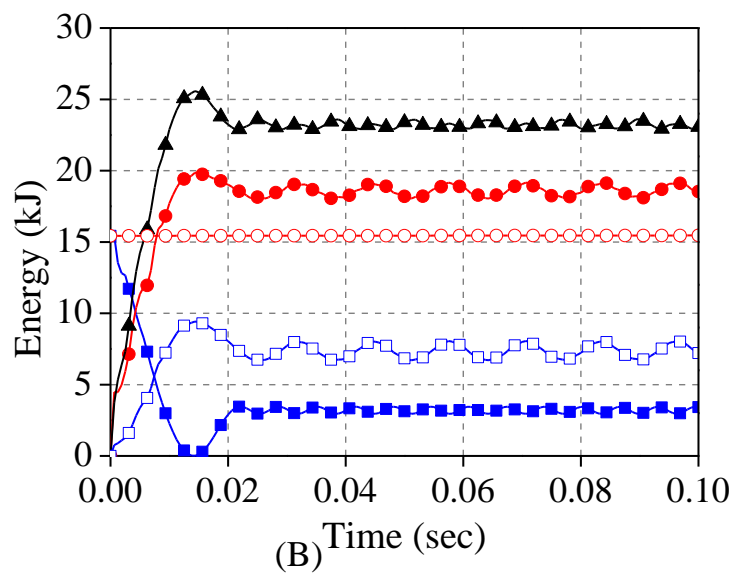

$\multimap-$ Total energy

Figure 10: Energy balance for the stable BC1 columns struck with a 15.4 kJ kinetic energy, impact height $=1.5 \mathrm{~m}$, preloading $=100 \%$. (A) Unstrengthened. (B) F3.

The energy balance for the column struck with a $15.4 \mathrm{~kJ}$ kinetic energy and $1.5 \mathrm{~m}$ impact height

was plotted in Figure 10. The main reason for plotting this figure was to show any potential instability as indicated by the kinetic energy history as explained earlier. This figure confirms 
that the column strengthened with the F3 configuration was stable during the entire analysis time because the kinetic energy completely dissipated then remained nearly unchanged, while for the un-strengthened column the kinetic energy increased suddenly from $0.015 \mathrm{sec}$, which indicates rapid movement (instability). In terms of the absorbed energy, it can also be seen from Figure 10 that the internal energy dissipated by the CFRP layers represented about $37 \%$ of the energy absorbed by the steel column.

\subsection{Columns with Boundary Condition 2 (BC2)}

Here the boundary condition at the column base was fixed and the corresponding value of the designed compression load increased. Similar to the previous simulations for BC1, the CFRP showed an excellent capability in preventing global buckling failure and shear failure in the steel column struck transversely as listed in Table 6. Except for the $289 \mathrm{~kJ}$ kinetic energy, no failure occurred for the strengthened column using the F3 CFRP configuration. It should be mentioned that the general trend of this simulation was usually similar to that occurring with the $\mathrm{BC} 1$ columns. Some differences are discussed in this section to avoid repetition. Table 6 shows that shear failure is more likely to occur when the impact location is close to the support. Similar findings were observed by other researchers such as Liu and Jones [31] who indicated that the transverse shear failure dominated when the impact point was close to a support.

Table 6: Failure modes of BC2 columns struck with a 1000 and $3000 \mathrm{~kg}$ mass.

\begin{tabular}{|c|c|c|c|c|c|c|c|c|}
\hline \multirow{3}{*}{ 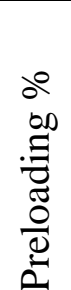 } & \multicolumn{4}{|c|}{ Impact velocity $=20 \mathrm{~km} / \mathrm{hr}(\mathrm{KE}=15.4 \mathrm{~kJ})$} & \multicolumn{4}{|c|}{ Impact velocity $=50 \mathrm{~km} / \mathrm{hr}(\mathrm{KE}=96.4 \mathrm{~kJ})$} \\
\hline & $\mathrm{U}$ & F1 & $\mathrm{F} 2$ & F3 & $\mathrm{U}$ & F1 & $\mathrm{F} 2$ & F3 \\
\hline & $\begin{array}{l}\text { Height } \\
\text { (m) }\end{array}$ & $\begin{array}{l}\text { Height } \\
\text { (m) }\end{array}$ & $\begin{array}{l}\text { Height } \\
\text { (m) }\end{array}$ & $\begin{array}{l}\text { Height } \\
\text { (m) }\end{array}$ & $\begin{array}{l}\text { Height } \\
\text { (m) }\end{array}$ & $\begin{array}{l}\text { Height } \\
\text { (m) }\end{array}$ & $\begin{array}{l}\text { Height } \\
\text { (m) }\end{array}$ & $\begin{array}{l}\text { Height } \\
\text { (m) }\end{array}$ \\
\hline
\end{tabular}




\begin{tabular}{|c|c|c|c|c|c|c|c|c|c|c|c|c|c|c|c|c|}
\hline & 0.5 & 1.5 & 0.5 & 1.5 & 0.5 & 1.5 & 0.5 & 1.5 & 0.5 & 1.5 & 0.5 & 1.5 & 0.5 & 1.5 & 0.5 & 1.5 \\
\hline 0 & $\mathrm{~S}$ & $\mathrm{~S}$ & $\mathrm{~S}$ & $\mathrm{~S}$ & $\mathrm{~S}$ & $\mathrm{~S}$ & $\mathrm{~S}$ & $\mathrm{~S}$ & $\mathrm{~S}$ & $\mathrm{~S}$ & $\mathrm{~S}$ & $\mathrm{~S}$ & $\mathrm{~S}$ & $\mathrm{~S}$ & $\mathrm{~S}$ & $\mathrm{~S}$ \\
\hline 25 & $\mathrm{~S}$ & $\mathrm{~S}$ & $\mathrm{~S}$ & $\mathrm{~S}$ & $\mathrm{~S}$ & $\mathrm{~S}$ & $\mathrm{~S}$ & $\mathrm{~S}$ & $\mathrm{~S}$ & $\mathrm{~S}$ & $\mathrm{~S}$ & $\mathrm{~S}$ & $\mathrm{~S}$ & $\mathrm{~S}$ & $\mathrm{~S}$ & $\mathrm{~S}$ \\
\hline 50 & $\mathrm{~S}$ & $\mathrm{~S}$ & $\mathrm{~S}$ & $\mathrm{~S}$ & $\mathrm{~S}$ & $\mathrm{~S}$ & $\mathrm{~S}$ & $\mathrm{~S}$ & $\mathrm{~S}$ & $\mathrm{~S}$ & $\mathrm{~S}$ & $\mathrm{~S}$ & $\mathrm{~S}$ & $\mathrm{~S}$ & $\mathrm{~S}$ & $\mathrm{~S}$ \\
\hline 75 & $\mathrm{~S}$ & $\mathrm{~S}$ & $\mathrm{~S}$ & $\mathrm{~S}$ & $\mathrm{~S}$ & $\mathrm{~S}$ & $\mathrm{~S}$ & $\mathrm{~S}$ & $\mathrm{SH}$ & G & $\mathrm{SH}$ & $\mathrm{SH}$ & SH & $\mathrm{S}$ & $\mathrm{S}$ & $\mathrm{S}$ \\
\hline 100 & SH & G & SH & G & $\mathrm{S}$ & $\mathrm{S}$ & $\mathrm{S}$ & $\mathrm{S}$ & SH & G & SH & SH & SH & G & $\mathrm{S}$ & $\mathrm{S}$ \\
\hline \multicolumn{17}{|c|}{ Impactor mass $=3000 \mathrm{~kg}$} \\
\hline \multirow{4}{*}{ 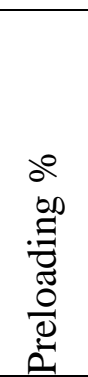 } & \multicolumn{8}{|c|}{ Impact velocity $=20 \mathrm{~km} / \mathrm{hr}(\mathrm{KE}=46.3 \mathrm{~kJ})$} & \multicolumn{8}{|c|}{ Impact velocity $=50 \mathrm{~km} / \mathrm{hr}(\mathrm{KE}=289 \mathrm{~kJ})$} \\
\hline & \multicolumn{2}{|l|}{$\mathrm{U}$} & \multicolumn{2}{|l|}{ F1 } & \multicolumn{2}{|l|}{ F2 } & \multicolumn{2}{|l|}{ F3 } & \multicolumn{2}{|l|}{$\mathrm{U}$} & \multicolumn{2}{|l|}{ F1 } & \multicolumn{2}{|l|}{$\mathrm{F} 2$} & \multicolumn{2}{|l|}{$\mathrm{F} 3$} \\
\hline & \multicolumn{2}{|c|}{$\begin{array}{l}\text { Height } \\
\text { (m) }\end{array}$} & \multicolumn{2}{|c|}{$\begin{array}{l}\text { Height } \\
\text { (m) }\end{array}$} & \multicolumn{2}{|c|}{$\begin{array}{l}\text { Height } \\
\text { (m) }\end{array}$} & \multicolumn{2}{|c|}{$\begin{array}{l}\text { Height } \\
\text { (m) }\end{array}$} & \multicolumn{2}{|c|}{$\begin{array}{l}\text { Height } \\
\text { (m) }\end{array}$} & \multicolumn{2}{|c|}{$\begin{array}{l}\text { Height } \\
\text { (m) }\end{array}$} & \multicolumn{2}{|c|}{$\begin{array}{l}\text { Height } \\
\text { (m) }\end{array}$} & \multicolumn{2}{|c|}{$\begin{array}{l}\text { Height } \\
\text { (m) }\end{array}$} \\
\hline & 0.5 & 1.5 & 0.5 & 1.5 & 0.5 & 1.5 & 0.5 & 1.5 & 0.5 & 1.5 & 0.5 & 1.5 & 0.5 & 1.5 & 0.5 & 1.5 \\
\hline 0 & $\mathrm{~S}$ & $\mathrm{~S}$ & $\mathrm{~S}$ & $\mathrm{~S}$ & $\mathrm{~S}$ & $\mathrm{~S}$ & $\mathrm{~S}$ & $\mathrm{~S}$ & $\mathrm{~S}$ & $\mathrm{~S}$ & $\mathrm{~S}$ & $\mathrm{~S}$ & $S$ & $\mathrm{~S}$ & $\mathrm{~S}$ & $S$ \\
\hline 25 & $\mathrm{~S}$ & $\mathrm{~S}$ & $\mathrm{~S}$ & $S$ & $\mathrm{~S}$ & $\mathrm{~S}$ & $\mathrm{~S}$ & $\mathrm{~S}$ & SH & $\mathrm{G}$ & SH & $\mathrm{S}$ & $\mathrm{S}$ & $\mathrm{S}$ & $\mathrm{S}$ & $\mathrm{S}$ \\
\hline 50 & $\mathrm{~S}$ & $\mathrm{~S}$ & $\mathrm{~S}$ & $\mathrm{~S}$ & $\mathrm{~S}$ & $\mathrm{~S}$ & $\mathrm{~S}$ & $\mathrm{~S}$ & SH & $\mathrm{G}$ & SH & $\mathrm{G}$ & SH & $\mathrm{G}$ & SH & $\mathrm{G}$ \\
\hline 75 & $S$ & $\mathrm{G}$ & $\mathrm{S}$ & $\mathrm{G}$ & $\mathrm{S}$ & $\mathrm{S}$ & $\mathrm{S}$ & $\mathrm{S}$ & & & & & & & & \\
\hline 100 & SH & $\mathrm{G}$ & SH & $\mathrm{G}$ & $\mathrm{S}$ & $\mathrm{S}$ & $S$ & $\mathrm{~S}$ & & & & & & & & \\
\hline
\end{tabular}

G: global buckling failure, S: stable and SH: transverse shear failure

Due to the negative moment at the fixed end, in some cases a local debonding of the CFRP occurred in this zone but the length of the debonded region was relatively small. This debonding especially occurred in the CFRP layer bonded to the column flange in the face directly opposite to the impacted surface.

As discussed earlier, the CFRP was able to prevent shear failure in many cases. In order to confirm the effectiveness of CFRP in preventing shear failure, Figure 11(A) illustrates the shear damage initiation criterion values (where a value of 1 indicates failure) for the un-strengthened and strengthened (F3) columns struck with a $15.4 \mathrm{~kJ}$ kinetic energy. The damage criterion was plotted for the centreline passing through the column web measured from the fixed end. The damage initiation criterion value for the un-strengthened column reached the maximum 
allowable value (1.0) while for the CFRP strengthened column the damage initiation value was around 0.2. This comparison reflects the excellent ability of the CFRP to enhance the steel column against transverse shear failure (see Figure 11(B)).

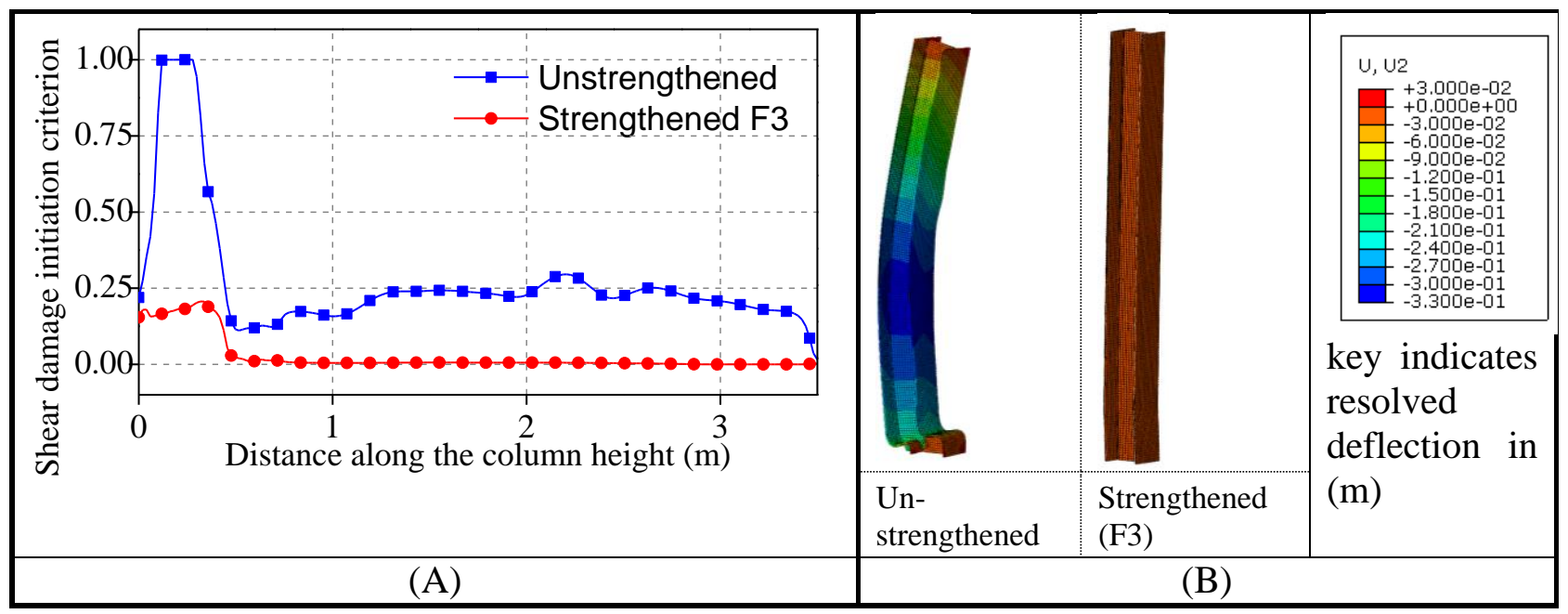

Figure 11: BC2 columns, comparison between (A) the shear damage initiation criterion value and (B) deformed shape, of the un-strengthened and strengthened (F3) columns (kinetic energy $=15.4 \mathrm{~kJ}$, impact location $=0.5 \mathrm{~m}$ and preloading level $=100 \%$ ) (All deformations having the same scale).

\section{Parametric study}

The aforementioned simulations, examined the influence of kinetic energy, impact location, boundary conditions and preloading level. All of these have been found to have significant effects on the performance of the un-strengthened and CFRP strengthened columns. In addition to the above, 3 other parameters namely the direction of impact, the length of the CFRP strengthening plate and the thickness of the CFRP plate, are separately investigated to ascertain their influence on column the behaviour.

\subsection{Influence of Impact direction}


Herein two impact directions on $\mathrm{BC} 1$ columns are examined: impact on the minor direction (i.e. at $90^{\circ}$ to the web) and at $45^{\circ}$ degrees to the web. Only configurations F2 and F3 will be included here since configuration F1 was found to have only minor improvement on the impact behaviour.

The simulation results showed that the CFRP had a good capability in preventing the column failure in many cases. The comparison was made with two values of kinetic energy. It was found that the CFRP effectiveness was not influenced by the impact direction in terms of the failure mode as listed in Table 7. Only one failure mode was observed in this simulation, which was the global buckling failure mode. As in previous simulations, no debonding was indicated except for that found in the end of the columns which was in all cases less than $0.1 \mathrm{~m}$. As mentioned earlier that this kind of debonding did not have a significant influence on the overall behaviour of the strengthening.

Table 7: Failure modes of columns struck with a $1000 \mathrm{~kg}$ mass (impact height $=1.5 \mathrm{~m}$ ).

\begin{tabular}{|c|c|c|c|c|c|c|c|c|c|c|c|c|}
\hline \multirow{3}{*}{ 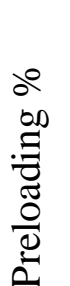 } & \multicolumn{6}{|c|}{ Angle of the impact $=90^{\circ}$ (minor direction) } & \multicolumn{6}{|c|}{ Angle of the impact $=45^{\circ}$} \\
\hline & \multicolumn{3}{|c|}{$\begin{array}{l}\text { Velocity }=20 \mathrm{~km} / \mathrm{hr} \\
(\mathrm{KE}=15.4 \mathrm{~kJ})\end{array}$} & \multicolumn{3}{|c|}{$\begin{array}{l}\text { Velocity }=50 \mathrm{~km} / \mathrm{hr} \\
(\mathrm{KE}=96.4 \mathrm{~kJ})\end{array}$} & \multicolumn{3}{|c|}{$\begin{array}{l}\text { Velocity }=20 \mathrm{~km} / \mathrm{hr} \\
(\mathrm{KE}=15.4 \mathrm{~kJ})\end{array}$} & \multicolumn{3}{|c|}{$\begin{array}{l}\text { Velocity }=50 \mathrm{~km} / \mathrm{hr} \\
(\mathrm{KE}=96.4 \mathrm{~kJ})\end{array}$} \\
\hline & $\mathrm{U}$ & F2 & F3 & $\mathrm{U}$ & $\mathrm{F}_{2}$ & F3 & $\mathrm{U}$ & $\mathrm{F} 2$ & F3 & $\mathrm{U}$ & $\mathrm{F} 2$ & F3 \\
\hline 0 & $\mathrm{~S}$ & $\mathrm{~S}$ & $\mathrm{~S}$ & $\mathrm{~S}$ & $\mathrm{~S}$ & $\mathrm{~S}$ & $\mathrm{~S}$ & $\mathrm{~S}$ & $\mathrm{~S}$ & S & $\mathrm{S}$ & $\mathrm{S}$ \\
\hline 25 & $\mathrm{~S}$ & $\mathrm{~S}$ & $\mathrm{~S}$ & $\mathrm{~S}$ & $\mathrm{~S}$ & $\mathrm{~S}$ & $\mathrm{~S}$ & $\mathrm{~S}$ & $\mathrm{~S}$ & $S$ & $\mathrm{~S}$ & $\mathrm{~S}$ \\
\hline 50 & $\mathrm{~S}$ & $\mathrm{~S}$ & $\mathrm{~S}$ & $\mathrm{~S}$ & $\mathrm{~S}$ & $\mathrm{~S}$ & $\mathrm{~S}$ & $\mathrm{~S}$ & $\mathrm{~S}$ & G & $\mathrm{S}$ & $\mathrm{S}$ \\
\hline 75 & $\mathrm{~S}$ & $\mathrm{~S}$ & $\mathrm{~S}$ & G & $\mathrm{G}$ & $\mathrm{S}$ & $\mathrm{S}$ & $\mathrm{S}$ & $\mathrm{S}$ & G & G & $\mathrm{S}$ \\
\hline 100 & $\mathrm{G}$ & $\mathrm{S}$ & $\mathrm{S}$ & $\mathrm{G}$ & $\mathrm{G}$ & $\mathrm{G}$ & $\mathrm{G}$ & $S$ & $S$ & $G$ & $\mathrm{G}$ & $\mathrm{G}$ \\
\hline
\end{tabular}

The deformation shape history for the columns struck with a $96.4 \mathrm{~kJ}$ energy at the minor axis is plotted in Figure 12. It can be seen from this figure that the location of the plastic hinge of the un-strengthened column approximately follows the first mode of the static global buckling shape. In addition, this figure illustrates how failure occurred in the un-strengthened column, while the strengthened columns remain stable under the same kinetic energy. 


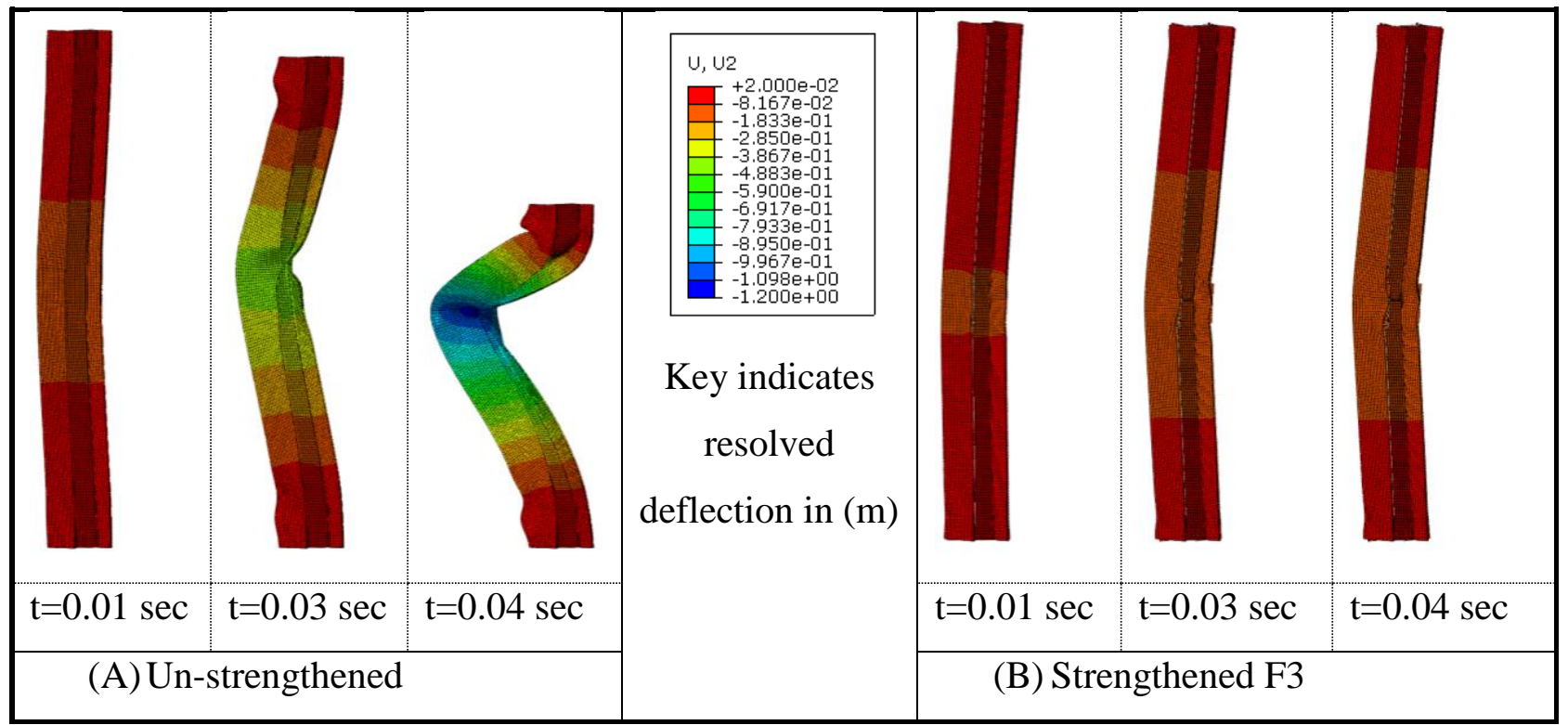

Figure 12: Deformed shape history of the $\mathrm{BC} 1$ columns $(\mathrm{F} 3)$, impact angle $=90^{\circ}$, kinetic energy $=$ $96.4 \mathrm{~kJ}$, impact height $=1.5 \mathrm{~m}$ and preloading level $=75 \%$. (All deformations having the same scale)

The results also indicate the plastic hinge location depends on the impact direction i.e., when the column is subjected to $45^{\circ}$ impact, the hinge location was normally at the impact location regardless of the boundary conditions and preloading level. It has been postulated that the plastic hinge location follows the first mode of the global buckling shape regardless of the impact location when the preloading level is more than $25 \%$ [28]. This may be because when the impact is applied at $45^{\circ}$ the impactor causes severe local distortion to the flange.

In terms of the transverse displacement, the value of maximum transverse displacement for the strengthened columns was in many cases $50 \%$ less than the corresponding value of the unstrengthened columns as shown in Figure 13. This finding was similar to that observed when the column was subjected to impact on the strong axis (major axis). However, some studies revealed that impact at the $90^{\circ}$ direction is the most critical situation in terms of the column vulnerability to global failure [28], while it is clear from Figure 13 that when the column was subjected to $45^{\circ}$ impact it almost always had more transverse displacement compared to impact at $90^{\circ}$. 


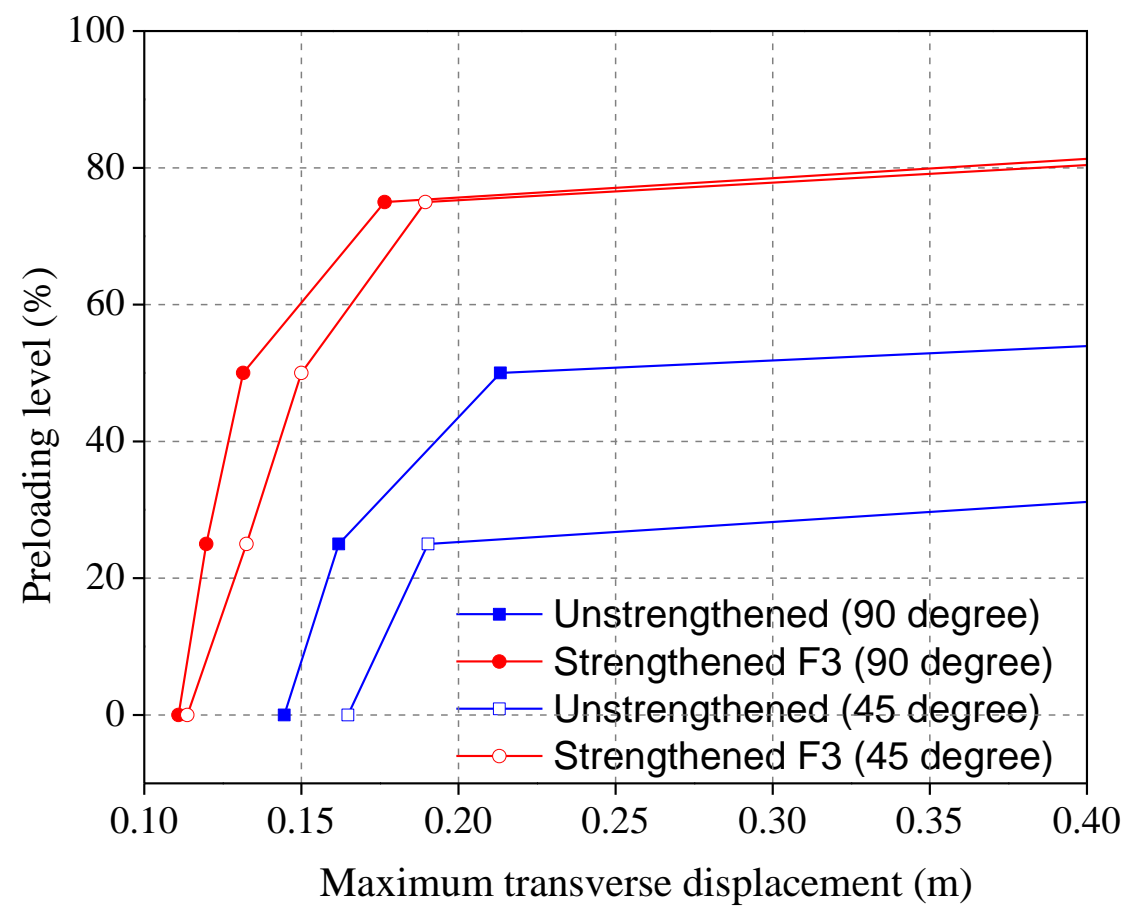

Figure 13: Maximum transverse displacement against preloading level for the column impacted with $90^{\circ}$ and $45^{\circ}$ angles, (Kinetic energy $=96.4 \mathrm{~kJ}$, impact height $=1.5 \mathrm{~m}$ ).

\subsection{Influence of CFRP length and location}

A BC2 column struck with a $15.4 \mathrm{~kJ}$ kinetic energy and $1.5 \mathrm{~m}$ impact height was chosen to investigate the influence of the CFRP configuration. In many cases, it is not practical/ economic to use CFRP strengthening along the entire length of the column, therefore this section investigates the use of shorter CFRP lengths. In the first step, a $3 \mathrm{~m}$ CFRP layer length which represents about $85 \%$ of the column length was used. This length was investigated using the F3 CFRP configuration. It was found that using this CFRP length starting either from the column base or centred about the column mid-height did not have a clear effect on the CFRP effectiveness compared to full length strengthening. Consequently, the CFRP length was reduced to $2 \mathrm{~m}$ ( $57 \%$ of the column length). At this stage, three different locations for the CFRP were investigated as shown in Figure 14. These three arrangements were chosen to find the most efficient CFRP location. In the third arrangement, the centre of the CFRP length was chosen to 
be on the same point as the intermediate plastic hinge which was expected to be around $65 \%$ of the column height [28] to prevent the global buckling.

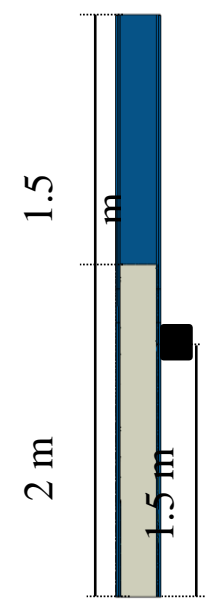

Location1

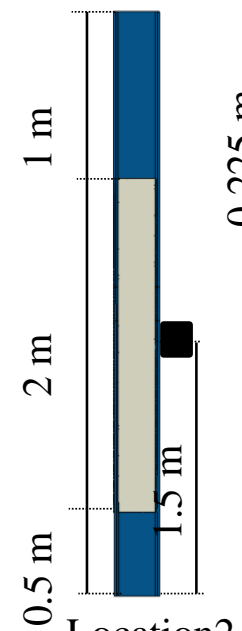

Location2

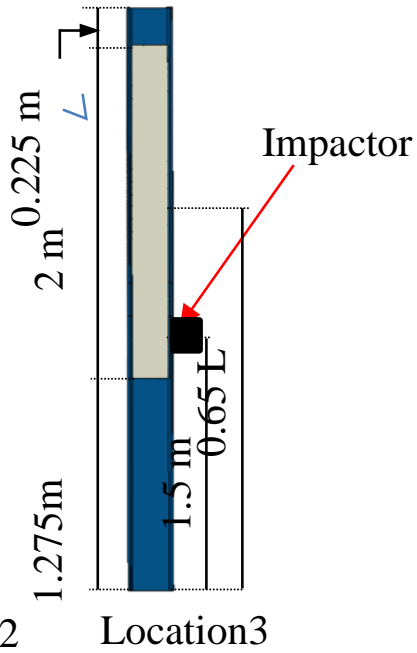

Location3

Figure 14: Location of the CFRP patch along the column height.

The simulation results showed that the first and second CFRP arrangements were not able to prevent global buckling of the column while the third arrangement successfully prevented column failure as shown in

Figure 15(A). The reason for this is that the failure mode of the un-strengthened column was found to be global buckling which approximately occurred at $0.65 \mathrm{~L}(\mathrm{~L}=$ column height) away from the column base. Consequently, applying CFRP at this point prevented global buckling failure. Thus, the failure mode for the strengthened column should be fully understood prior to choosing the length and location of the CFRP patch. To confirm the column instability, the kinetic energy history for all suggested CFRP locations was plotted in

Figure 15(B). It is clear from this figure that the first and second CFRP arrangements failed at 0.03 and $0.02 \mathrm{sec}$ after the start of impact respectively. 


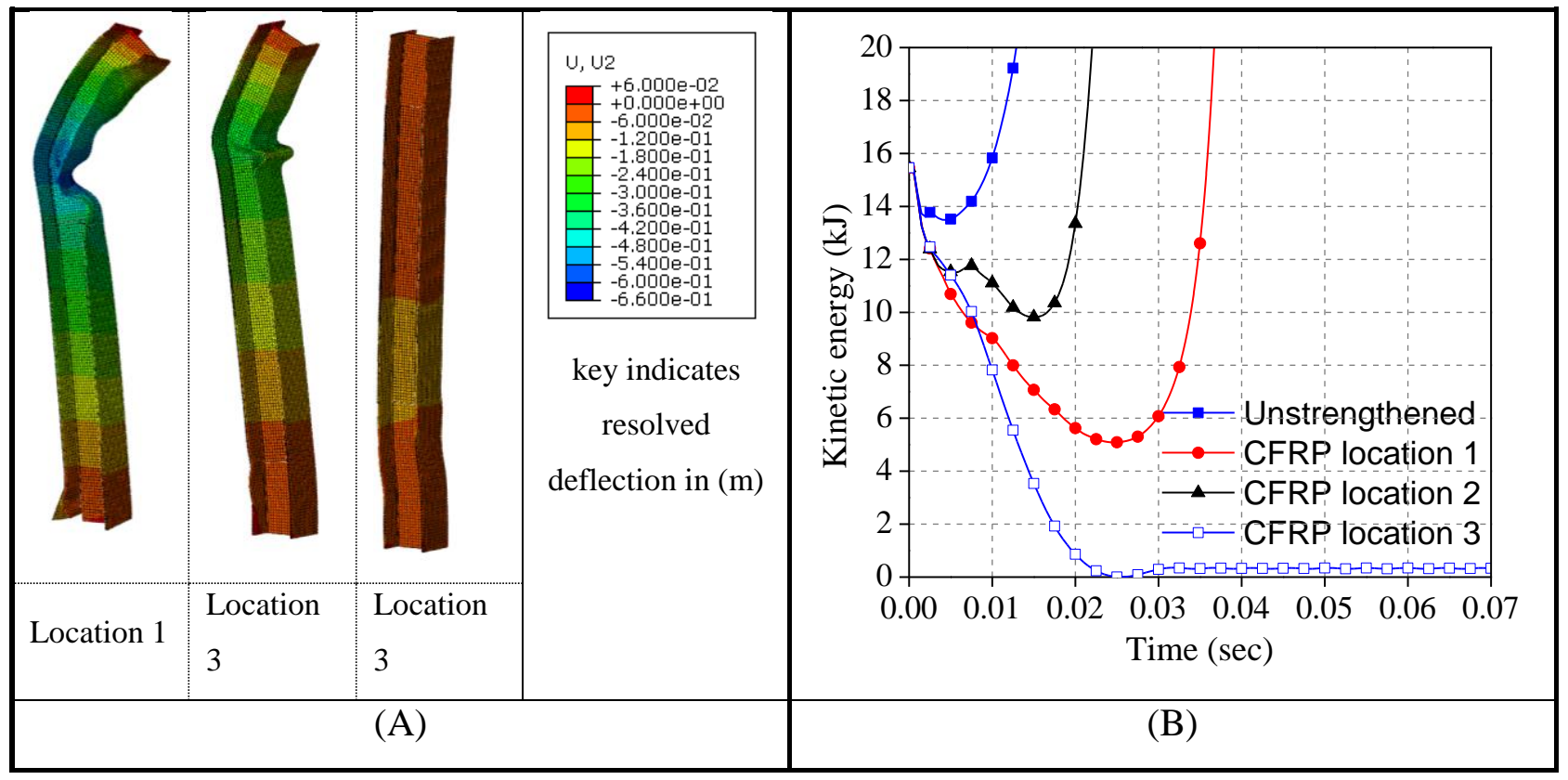

Figure 15: (A) Deformed shape (All deformations having the same scale) and (B) Kinetic energy history of the columns strengthened with various CFRP patch locations $(\mathrm{CFRP}$ length $=2 \mathrm{~m}, \mathrm{KE}=$ $15.4 \mathrm{~kJ}$, impact location $=1.5 \mathrm{~m}$, preloaidng level $=100 \%, \mathrm{BC} 2)$.

\subsection{Influence of CFRP thickness}

In all previous simulations, the thickness of the CFRP layers was kept constant at $5 \mathrm{~mm}$. However, in order to examine the exact thickness that is needed to prevent a column failure, several CFRP thicknesses were examined in thi\$Bfetion. Two different cases were chosen from Table 6: the $\mathrm{BC} 2$ un-strengthened columns under kinetic energy $\mathrm{KE}=15.4 \mathrm{~kJ}$, impact height $=1.5 \mathrm{~m}$, preloading level $=100 \%$ and $\mathrm{KE}=96.4 \mathrm{~kJ}$, impact height $=1.5 \mathrm{~m}$, preloading level $=75 \%$. In these two cases, the un-strengthened columns globally buckled while using the CFRP configuration F3 helped to maintain stability. Four different thicknesses for the CFRP layers were examined in addition to the original thickness (5 mm) including 1, 2, 3 and $4 \mathrm{~mm}$.

The results plotted in Figure 16(A) demonstrate that reducing the CFRP thickness to some extent did not have an effect on the stability of the column even if it caused an increase in the maximum 
transverse displacement. Figure 16(B) shows that when the CFRP thickness was $\geq 2 \mathrm{~mm}$ the columns were stable.

The required thickness of the CFRP layers can be selected based on the maximum stresses reached at each layer. Here it is useful to consider the fibre tensile damage initiation criterion value which is a function of stress in the longitudinal direction (fibre direction) of the CFRP layer positioned in the direction opposite to the impact face. For the 2, 3 and $4 \mathrm{~mm}$ CFRP, the tensile damage initiation value (where a value of 1 indicates failure) peaked at between $0.1(4 \mathrm{~mm}$ CFRP) and 0.2 (2mm CFRP) after around 0.01s and remained constant thereafter. However in the case of the $1 \mathrm{~mm}$ thick sheet the value steadily increased and approached 1 at around $0.06 \mathrm{~s}$. This demonstrates that reducing CFRP thickness can cause a significant increase in the damage criterion value which reflects the increases in the stress along the longitudinal direction.

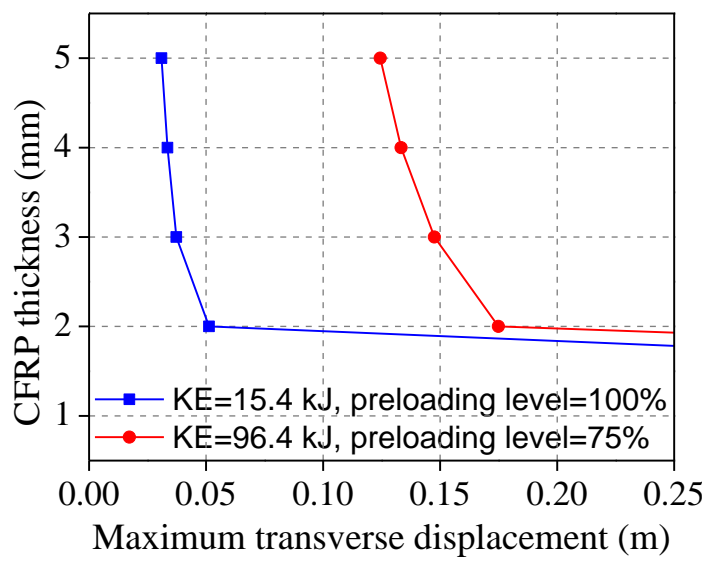

(A)

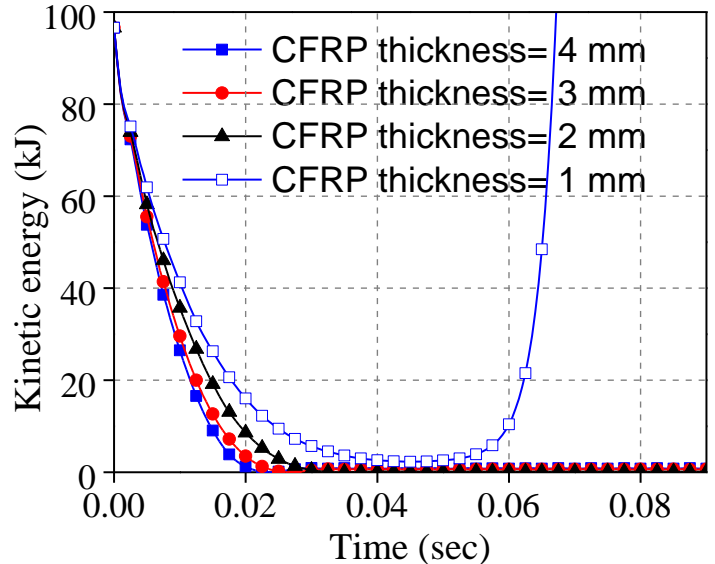

(B)

Figure 16: (A) Maximum transverse displacement (B) Kinetic energy histories KE=96.4 kJ, impact height $=1.5 \mathrm{~m}$, preloading level $=75 \%$, for various CFRP thicknesses.

In many cases using CFRP did not change the failure mode for strengthened columns. For example, the BC1 column struck with a $96.4 \mathrm{~kJ}$ kinetic energy (impact height $1.5 \mathrm{~m}$, preloading level $=75 \%)($ see Table 5) failed even when the F3 strengthening scheme was used. Based on the discussion in the previous paragraph, the thickness of the CFRP layers has a clear effect on the failure mode of strengthened columns. Consequently, the CFRP thickness was increased to 6, 7 
and $8 \mathrm{~mm}$ to find out whether this increase can prevent instability under the same loading conditions. It was found that a CFRP plate thickness of $7 \mathrm{~mm}$ ensured stability. Further increases in the CFRP thickness had only a small effect on the maximum transverse displacement value.

\section{Conclusions}

This study presents a series of numerical simulations aimed at examining the effectiveness of CFRP in strengthening full-scale H-section steel columns. The main aim of the strengthening is to prevent column failure as a result of an impact event. The following conclusions may be drawn from this study:

- The numerical model presented was demonstrated to be capable of capturing global buckling failure and transverse shear failure accompanying dynamically loaded columns.

- The CFRP strengthening technique was found to be highly capable in preventing column failure such as global buckling failure and transverse shear failure.

- For stable columns, externally bonded CFRP can reduce the transverse displacement and the axial displacement by more than $70 \%$ in many cases.

- The high effectiveness of the CFRP in strengthening steel columns has been found to be similar for both the studied boundary conditions.

- The direction of impact did not have a clear influence on the effectiveness of the CFRP for the various angles examined i.e. $45^{\circ}$ and $90^{\circ}$.

- The main parameters that influence the CFRP effectiveness are the dimensions of the CFRP itself. By using various thicknesses and lengths of the CFRP patch, the behaviour of the strengthened column can be varied from global failure to stable. Thus, the dimensions of the CFRP strengthening layers should be selected carefully. 
- Based on the findings of this study, it can be concluded that the CFRP strengthening technique can offer a practical and effective solution to protection of existing steel columns against impact load. The work presented here is limited to specific column geometry, load and boundary conditions. Hence more research is needed to establish comprehensive guidelines that can be used by designers. This forms part of the authors' on-going work.

\section{Acknowledgments}

Our thanks to the Ministry of Higher Education and Scientific Research in Iraq for funding this research. Thanks are also due to the technical staff at the School of Mechanical, Aerospace and Civil Engineering, University of Manchester, for facilitating the experimental work.

\section{References}

[1] J. Scheer, Failed bridges: case studies, causes and consequences, John Wiley \& Sons, Germany, 2011.

[2] H. Al-Thairy, Y.C. Wang, A numerical study of the behaviour and failure modes of axially compressed steel columns subjected to transverse impact, International Journal of Impact Engineering 38(8) (2011) 732-744.

[3] H. Al-Thairy, and Y. C. Wang, An assessment of the current Eurocode 1 design methods for building structure steel columns under vehicle impact, Journal of Constructional Steel Research 88 (2013) 164-171.

[4] A. Peiris, I. Harik, Field Testing of Steel Bridge Girders Strengthened Using Ultra High Modulus (UHM) Carbon Fiber Reinforced Polymer (CFRP) Laminates, The 6th International Conference on FRP Composites in Civil Engineering, Rome, Italy, 2012, pp. 13-15.

[5] V.M. Karbhari, Rehabilitation of Metallic Civil Infrastructure Using Fiber Reinforced Polymer (FRP) Composites: Types Properties and Testing Methods, Woodhead publishing, Cambridge, 2014.

[6] E. Ghafoori, A. Schumacher, M. Motavalli, Fatigue behavior of notched steel beams reinforced with bonded CFRP plates: Determination of prestressing level for crack arrest, Engineering structures 45 (2012) 270-283.

[7] Y.J. Kim, K.A. Harries, Fatigue behavior of damaged steel beams repaired with CFRP strips, Engineering Structures 33(5) (2011) 1491-1502.

[8] J. Deng, M.M. Lee, Behaviour under static loading of metallic beams reinforced with a bonded CFRP plate, Composite Structures 78(2) (2007) 232-242. 
[9] M. Kadhim, Effect of CFRP plate length strengthening continuous steel beam, Construction and Building Materials 28(1) (2012) 648-652.

[10] H.A. Al-Zubaidy, X.-L. Zhao, R. Al-Mahaidi, Dynamic bond strength between CFRP sheet and steel, Composite Structures 94(11) (2012) 3258-3270.

[11] H.A. Al-Zubaidy, R. Al-Mahaidi, X.-L. Zhao, Finite element modelling of CFRP/steel double strap joints subjected to dynamic tensile loadings, Composite Structures 99 (2013) 48-61.

[12] A. Al-Mosawe, R. Al-Mahaidi, X.-L. Zhao, Experimental and Numerical Study on Strengthening of Steel Members Subjected to Impact Loading Using Ultrahigh Modulus CFRP, Journal of Composites for Construction (2016) 04016044.

[13] A. Al-Mosawe, R. Al-Mahaidi, X.-L. Zhao, Bond behaviour between CFRP laminates and steel members under different loading rates, Composite Structures 148 (2016) 236-251.

[14] M.I. Alam, S. Fawzia, Numerical studies on CFRP strengthened steel columns under transverse impact, Composite Structures 120 (2015) 428-441.

[15] M. Kadhim, Z. Wu, L. Cunningham, FE modelling of CFRP strengthened steel members under impact loads, Proceedings of the 24th UK Conference of the Association for Computational Mechanics in Engineering, Cardiff University, Cardiff, UK, 2016, pp. 343-346.

[16] M.I. Alam, S. Fawzia, X.-L. Zhao, A.M. Remennikov, Experimental Study on FRPStrengthened Steel Tubular Members under Lateral Impact, Journal of Composites for Construction 21(5) (2017) 04017022.

[17] M. Kadhim, Z. Wu, L. Cunningham, Experimental study of CFRP strengthened steel columns subject to lateral impact loads, Composite Structures 185(1) (2018) 94-104.

[18] M. Kadhim, Z. Wu, L. Cunningham, Effects of loading rate on the behaviour of CFRP strengthened steel members, Fourth International Conference on Smart Monitoring, Assessment and Rehabilitation of Civil Structures, Zurich, Switzerland, 2017.

[19] M. Zeinoddini, G. Parke, J. Harding, Axially pre-loaded steel tubes subjected to lateral impacts: an experimental study, International Journal of Impact Engineering 27(6) (2002) 669690.

[20] J. Yu, N. Jones, Further experimental investigations on the failure of clamped beams under impact loads, International Journal of Solids and Structures 27(9) (1991) 1113-1137.

[21] BSI, BS EN 1993-1-1: Eurocode 3: Design of steel structures - Part 1-1: General rules and rules for buildings, British Standards Institution, London, 2005.

[22] N. Jones, Structural impact, Cambridge University Press, Cambridge, 1997.

[23] M.M. Kadhim, Z. Wu, L.S. Cunningham, Loading rate effects on CFRP strengthened steel square hollow sections under lateral impact, Engineering Structures 171 (2018) 874-882.

[24] Z. Hashin, Failure criteria for unidirectional fiber composites, Journal of Applied Mechanics 47(2) (1980) 329-334.

[25] Huntsman, Structural adhesives aerospace adhesives araldite 420A/B, 2009. $<$ https://www.huntsmanservice.com/>.

[26] F. Dolce, Blast impact simulation on composite military armours, University of Bath, 2009.

[27] SIMULIA, Analysis user's manual, Providence, Rhode Island, USA., SIMULIA, Dassault Systèmes (2013).

[28] H. Al-Thairy, Behaviour and design of steel columns subjected to vehicle impact, University of Manchester, 2012.

[29] BSI, BS EN 1991-1-7:2006, Eurocode 1 - Actions on structures - Part 1-7: General actions - Accidental actions, Incorporating corrigendum February 2010, British Standards Institution, London, 2006. 
[30] T. Adachi, T. Tanaka, A. Sastranegara, A. Yamaji, S.-K. Kim, I.-Y. Yang, Effect of transverse impact on buckling behavior of a column under static axial compressive force, International Journal of Impact Engineering 30(5) (2004) 465-475.

[31] J. Liu, N. Jones, Experimental investigation of clamped beams struck transversely by a mass, International Journal of Impact Engineering 6(4) (1987) 303-335. 